\title{
Viral subversion of the host protein synthesis machinery
}

Derek Walsh ${ }^{* \S}$ and Ian Mohr

Abstract | Viruses are fully reliant on the translation machinery of their host cells to produce the polypeptides that are essential for viral replication. Consequently, viruses recruit host ribosomes to translate viral mRNAs, typically using virally encoded functions to seize control of cellular translation factors and the host signalling pathways that regulate their activity. This not only ensures that viral proteins will be produced, but also stifles innate host defences that are aimed at inhibiting the capacity of infected cells for protein synthesis. Remarkably, nearly every step of the translation process can be targeted by virally encoded functions. This Review discusses the diverse strategies that viruses use to subvert host protein synthesis functions and regulate mRNA translation in infected cells.

7-methylguanosine cap A 7-methylguanosine linked to the $5^{\prime}$ end of an mRNA, via a $5^{\prime}-5^{\prime}$ triphosphate linkage, to mark the extreme $5^{\prime}$ terminus of a eukaryotic mRNA. In addition to having regulatory roles in pre-mRNA processing and mRNA stability, the cap structure controls ribosome recruitment to the mRNA $5^{\prime}$ end.

* National Institute for Cellular Biotechnology, Dublin City University,

Dublin 9, Ireland. ${ }^{\ddagger}$ Department of Microbiology and New York University Cancer Institute, New York University School of Medicine, New York, New York 10016, USA.

sPresent address:

Department of Microbiology, New York University School of Medicine, New York, New York 10016, USA. Correspondence to D.W. and I.M. e-mails:

derek.walsh@nyumc.org; ian.mohr@med.nyu.edu doi:10.1038/nrmicro2655 Published online

17 October 2011
Despite the diverse functions that viruses encode for their propagation, they remain exquisitely dependent on the translational machinery of the host cell. No matter whether their genomes are RNA or DNA, and regardless of their mRNA production method, the goal remains the same: to ensure that cellular ribosomes are recruited to viral mRNAs. The ensuing synthesis of viral proteins is required for viral genome replication and progeny virion production. Typically, commandeering ribosomes to viral mRNAs involves subverting cellular translation factors and signalling pathways that control the host protein synthesis apparatus. Many discrete strategies have been uncovered by studying translation control in virus-infected cells. These investigations have not only revealed key steps in viral pathogenesis, but also defined paradigms for translation control in uninfected cells. In this Review, we discuss the underlying mechanisms by which viruses gain control over the cellular functions required for mRNA translation.

\section{Translation regulation: the basics}

Regulated mRNA translation is a post-transcriptional mechanism that controls gene expression and directly and rapidly varies protein abundance, both spatially and temporally. It has a major role in numerous biological processes, including cell growth, development, synaptic plasticity, stress responses and productive viral growth. Viruses not only need unrestricted access to the host translation machinery, but also must suppress host innate defences that are designed to cripple the protein production capacity of the infected cell. The translation process can be subdivided into three stages - initiation, elongation and termination - each of which requires specific factors (FIG. 1). Much of the regulation of this process focuses on the rate-limiting initiation step, which involves ribosome recruitment to mRNA.

Prior to their recruitment to mRNAs, 40 S ribosome subunits bind to the eukaryotic translation initiation factor 1 (eIF1), eIF1A, the eIF3 complex and eIF5, along with eIF2.GTP, to assemble a $43 \mathrm{~S}$ pre-initiation complex loaded with the charged initiator-methionine tRNA (Met-tRNA $\mathrm{i}_{\mathrm{i}}$. Unlike bacterial mRNAs, most eukaryotic mRNAs cannot position ribosomes on their $5^{\prime}$ termini to initiate translation. Instead, eIFs recognize structural landmarks in the mRNA to load $40 \mathrm{~S}$ subunits onto the transcript. The 7-methylguanosine cap $\left(\mathrm{m}^{7} \mathrm{G}\right)$ that distinguishes the $5^{\prime}$ end of the eukaryotic mRNA is bound by eIF4F, a multisubunit complex comprising the capbinding protein eIF4E and the DEAD box-containing RNA helicase eIF4A, both bound to the large molecular scaffold eIF $4 \mathrm{G}^{1}$. Cap recognition by eIF4E anchors the complex on the mRNA, and eIF4G binding enhances the affinity of eIF4E for the cap. Indeed, eIF4E binding to eIF4G represents a crucial step in which physiological inputs regulate eIF4F assembly and translation initiation. Integration of signals relating to nutrient availability and energy supply, as well as growth factor signals, by the kinase complex mTOR complex 1 (mTORC1) regulates the translation repressor eIF4E-binding protein 1 (4EBP1), which binds eIF4E and suppresses eIF4F assembly. Hyperphosphorylation of 4EBP1 by activated mTORC1 liberates eIF4E, allowing eIF4G to bind eIF4E and stimulate cap-dependent translation (FIG. 2). Following eIF4E incorporation into eIF4F, eIF4E can be 
a Initiation
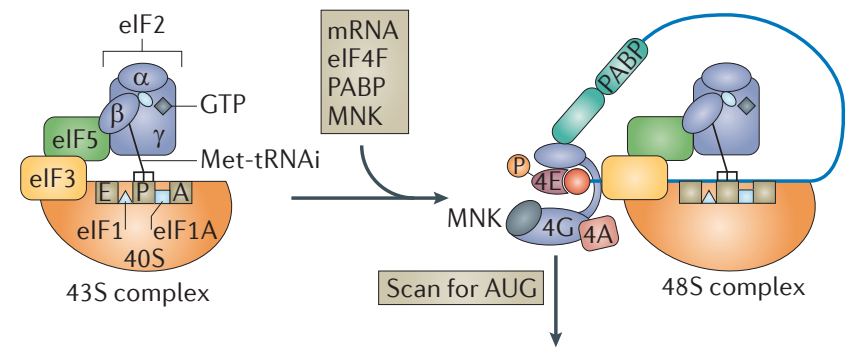

b Elongation

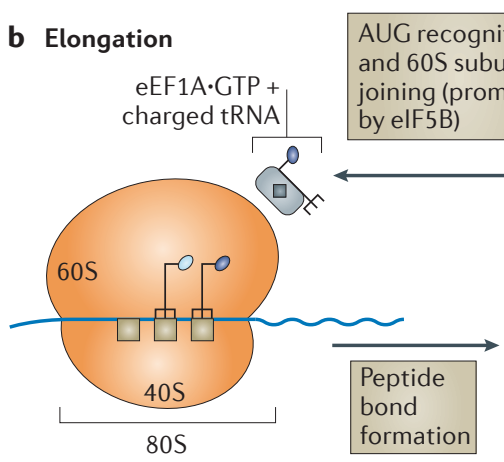

d
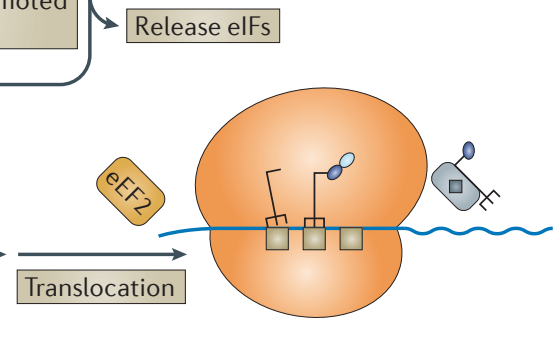

c Termination
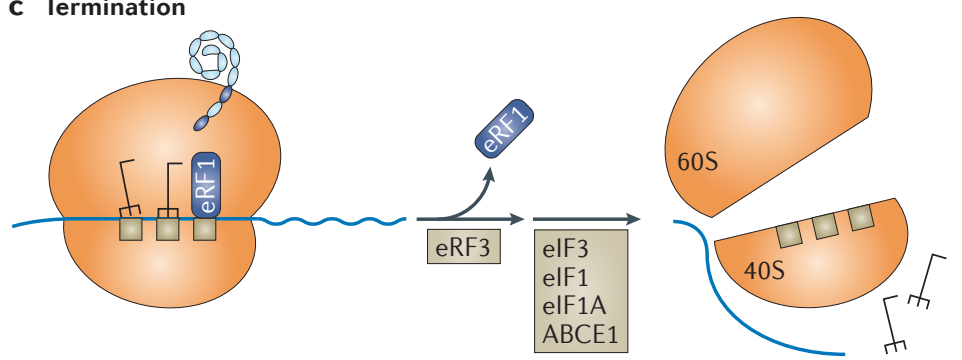

Figure 1 | Overview of mRNA translation in eukaryotes. The process of translation has three phases: initiation, elongation and termination. Each stage requires specific translation factors. a | Initiation. The $40 \mathrm{~S}$ ribosome bound to eukaryotic translation initiation factor 1 (elF1), elF1A, the elF3 complex and elF5 is loaded with initiatormethionine tRNA (Met-tRNA ) in the $P$ site by elF2.GTP, forming a $43 \mathrm{~S}$ pre-initiation complex. Subsequently, the $43 \mathrm{~S}$ complex is positioned onto the $5^{\prime}$ end of a capped (red circle), polyadenylated mRNA by elF4F, a multisubunit complex composed of the cap-binding protein elF4E, elF4G and elF4A (abbreviated here as 4E, 4G and 4A). The polyadenylated $3^{\prime}$ mRNA end is recognized by a poly(A)-binding protein (PABP), which also associates with elF4G bound to the $5^{\prime}$ end. This results in a 'closed-loop' topology, linking $5^{\prime}$ and $3^{\prime}$ mRNA ends. One of the elF4E kinases MNK1 and MNK2 binds elF4G and phosphorylates elF4E. The assembled $48 \mathrm{~S}$ complex then scans the mRNA to locate the AUG start codon. After AUG recognition, facilitated by elF3, elF1 and 1A, 60S subunit joining triggers initiation factor release. $\mathbf{b}$ | Elongation. Each charged tRNA is delivered to the $80 \mathrm{~S}$ ribosome A site by eEF1A.GTP. Following ribosome-catalysed peptide bond formation, eukaryotic elongation factor 2 (eEF2) catalyses $80 S$ translocation, transferring the deacetylated tRNA to the $E$ site, positioning the peptidyl-tRNA in the $P$ site and re-exposing the A site. $\mathbf{c}$ | Termination. Eukaryotic release factor 1 (eRF1) recognizes the stop codon in the A site, triggering $80 \mathrm{~S}$ arrest and polypeptide release. eRF3 releases eRF1 from the ribosome, and several initiation factors, together with ABCE1-directed nucleotide hydrolysis, dismantle the complex, thus recycling ribosome subunits.

phosphorylated by an eIF4G-associated kinase (either MNK1 or MNK2). Whereas basal eIF4E phosphorylation requires $\mathrm{MNK} 2$, inducible p38 mitogen-activated protein kinase family-responsive and extracellular signal-regulated kinase (ERK)-responsive eIF4E phosphorylation is MNK1 dependent. eIF4F assembly coordinates the interactions of the $5^{\prime}$ and $3^{\prime}$ mRNA ends, as a poly(A)-binding protein (PABP) recognizes the $3^{\prime}$ terminus of the polyadenylated mRNA and associates with eIF4G to stimulate initiation. This interaction probably restricts recruitment of the $40 \mathrm{~S}$ ribosome to mRNAs with intact $5^{\prime}$ and $3^{\prime}$ termini ${ }^{1}$. Thus, in eukaryotes, regulated assembly of a specialized ribonucleoprotein complex including eIF4F and PABP facilitates $40 \mathrm{~S}$ subunit loading onto mRNA (FIG. 1). This key initiation step is rate limiting, and the degree to which individual mRNAs are reliant on high or low eIF4F levels depends on the extent of secondary structure in the $5^{\prime}$ untranslated region (UTR).

Although regulated eIF4F assembly marks the mRNA $5^{\prime}$ end and controls 40S subunit recruitment, eIF4F does not directly tether ribosomes to mRNA. eIF3 bridges the eIF4F cap recognition complex and the $43 \mathrm{~S}$ preinitiation complex ${ }^{1}$. After positioning the $40 \mathrm{~S}$ subunit onto the $5^{\prime}$ end of the mRNA, the AUG start codon is identified by a process termed scanning. By binding $40 \mathrm{~S}$ subunits, eIF3 also prevents $60 \mathrm{~S}$ subunits from joining during scanning and initiation.

The recognition of AUG and the joining of the $60 \mathrm{~S}$ subunit triggers the release of initiation factors, and the $80 \mathrm{~S}$ ribosome subsequently begins polypeptide chain elongation (FIG. 1). As well as maintaining the correct reading frame, elongation requires a limited set of eukaryotic elongation factors (eEFs). eEF1A delivers each selected aminoacylated tRNA to the 80S ribosome A site. Ribosome-catalysed peptide bond formation precedes eEF2-mediated ribosome translocation along the mRNA. To regulate elongation, phosphorylation by CK2 (also known as casein kinase II) and protein kinase C (PKC) family kinases stimulates eEF1A, whereas phosphorylation by eEF2 kinase inhibits eEF2 activity. Chain elongation proceeds until a stop codon prompts termination ${ }^{2}$.

Stop codon recognition by eRF1 induces hydrolysis of the ester bond linking the tRNA to the completed polypeptide, resulting in translation termination (FIG. 1). eRF3 then removes eRF1 from the ribosome $e^{3}$. Posttermination ribosomes are dismantled into $60 \mathrm{~S}$ and $40 \mathrm{~S}$ components, promoting subunit recycling and the release of mRNA and tRNAs. This ensemble of cellular translation initiation, elongation and termination factors is regulated by an intricate web of signals, providing viruses with numerous potential targets through which they can commandeer the host protein synthesis machinery.

\section{Targeting initiation through elF4F}

Regulated eIF4F assembly is a fundamental step in controlling cap-dependent translation initiation in eukaryotes. Given the importance of protein synthesis in the biology of viruses, it is no wonder viruses target eIF4F to subvert and gain control of the host translational apparatus (FIG. 2). Some viruses impair host translation by removing key structural elements in the mRNA, such as the $\mathrm{m}^{7} \mathrm{G}$ cap, by inactivating eIF4F subunits or by manipulating eIF4F-binding proteins, thus preventing synthesis of host defence molecules that antagonize viral 


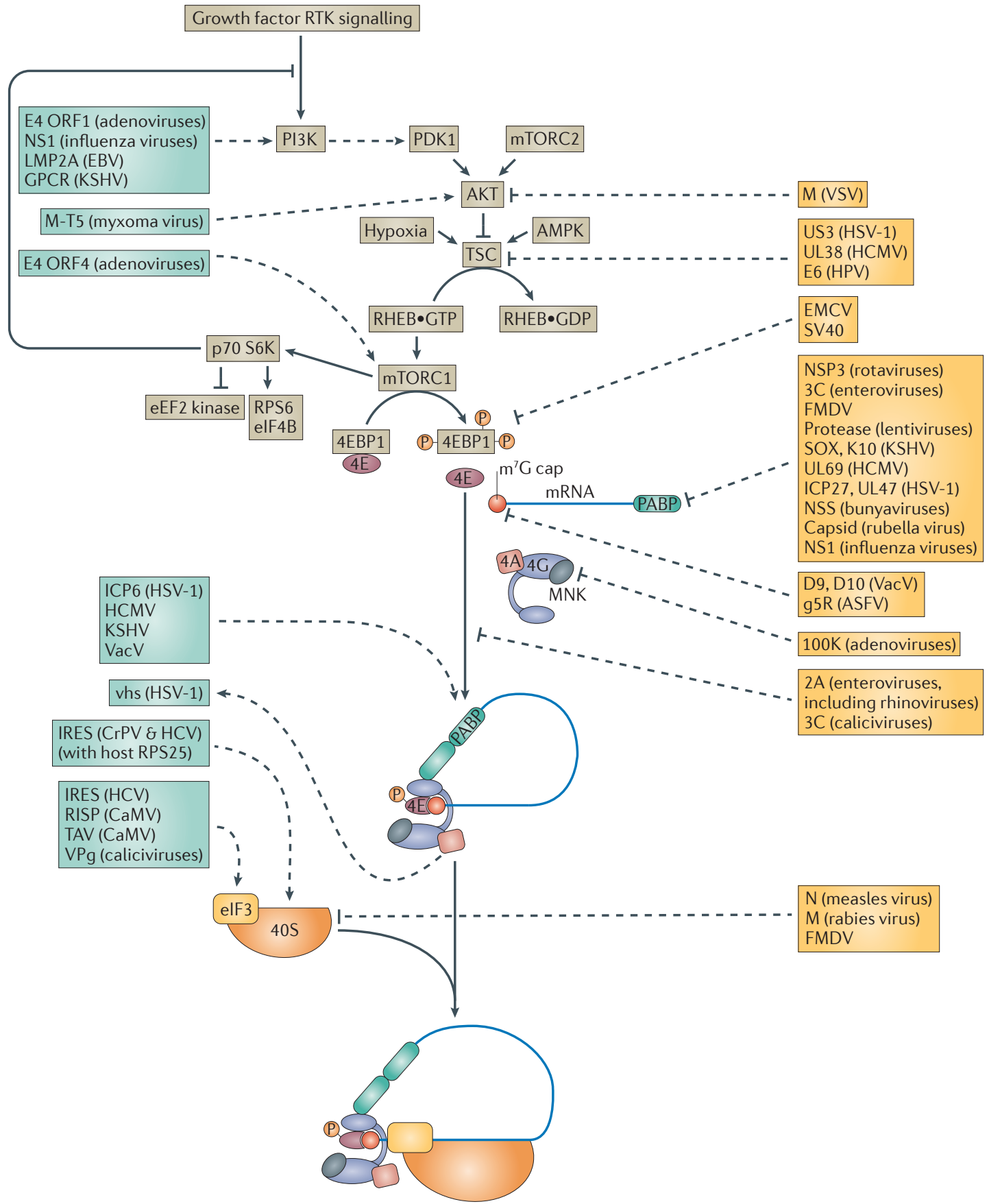

Figure 2 | Control of cap-dependent translation by regulated assembly of a multisubunit initiation factor. By binding to the cap-binding protein eukaryotic translation initiation factor $4 \mathrm{E}$ (elF4E; abbreviated here to 4E), elF4E-binding protein 1 (4EBP1) represses translation and prevents assembly of the multisubunit initiation factor elF4F (composed of elF4E, elF4A (labelled 4A) and elF4G (labelled 4G)). The GTPase-activating protein TSC (composed of subunits hamartin (TSC1) and tuberin (TSC2)) represses mTOR complex 1 (mTORC1) by promoting RHEB.GDP accumulation. Receptor tyrosine kinase signalling, AMP-activated protein kinase (AMPK) and hypoxia regulate TSC activity. Inhibiting TSC allows RHEB.GTP accumulation and mTORC1 activation, and results in p70 ribosomal protein S6 kinase (p70 S6K) and 4EBP1 phosphorylation. 4EBP1 hyperphosphorylation relieves translational repression and releases elF4E, allowing elF4E to bind elF4G and assemble elF4F on 7-methylguanosine ( $m^{7} \mathrm{G}$; red circle)-capped mRNA. elF4F assembly typically results in elF4E phosphorylation by the elF4G-associated kinases (the MNK proteins) and recruits the $43 \mathrm{~S}$ complex (see FIG. 1 a) containing the 40 S ribosome. A poly(A)-binding protein (PABP) is depicted bound to the 3' poly(A) tail, and this PABP associates with elF4G to stimulate translation. In addition to stimulating ribosomal protein S6 (RPS6) phosphorylation, p70 S6K activation by mTORC1 stimulates the elF4A accessory factor elF4B and inhibits eukaryotic elongation factor 2 (eEF2) kinase, thereby stimulating elongation. Importantly, by repressing phosphoinositide 3-kinase (PI3K) activation, p70 S6K activation prevents constitutive mTORC1 activation. Viral strategies for activating (green) and inhibiting (yellow) elF4F are indicated; see main text for details and abbreviations. 
replication. Other viruses stimulate eIF4F to translate their mRNAs, or change the subcellular distribution of eIF4F subunits to suit their needs.

Targeting eIF4F recruitment. Translation of most host mRNAs via a cap-dependent mechanism allows viruses to impair cellular protein synthesis by altering the recognition of host mRNAs by eIF4F. For example, poxviral decapping enzymes remove the $\mathrm{m}^{7} \mathrm{G} \mathrm{cap}^{4,5}$, whereas influenza viruses and hantaviruses 'steal' caps together with a $5^{\prime}$-proximal 10-18-nucleotide host mRNA segment that is used to prime viral mRNA synthesis ${ }^{6-8}$. Despite this removal of eIF4F-binding determinants on host mRNAs, eIF4F components can still be recruited to viral transcripts. For instance, influenza virus RNA polymerase and NS1 interact with eIF4G to recruit eIF4F to viral mRNAs ${ }^{9}$. Other viral genomes contain genes encoding cap substitutes. The $5^{\prime}$ ends of mRNAs from mammalian caliciviruses (such as noroviruses and plant potyviruses) are not capped but, instead, are covalently linked to a viral protein, VPg, that binds host initiation factors to recruit ribosomes ${ }^{10-12}$. The $5^{\prime} \mathrm{mRNA}$ leader of potyviruses, which are related to picornaviruses, contains eIF4G-binding pseudoknots that direct cap-independent translation ${ }^{13}$. Other plant viruses contain $3^{\prime}$ cap-independent translational elements (CITEs), which interact with the 5 ' end of the mRNA and bind initiation factors, including eIF4E and eIF4G, to recruit ribosomes ${ }^{14}$. For example, the turnip crinkle virus (TCV) CITE contains tRNA-like structures that bind the 60S ribosome $\mathrm{e}^{15} .3^{\prime}$ CITES also suppress mRNA translation on positive-strand RNAs to promote genome replication ${ }^{14}$. Finally, hantavirus N protein reportedly has cap-binding, RNA-binding, helicase and ribosome-binding activities, substituting for eIF4F to promote translation of viral mRNAs ${ }^{16}$.

Internal ribosome entry sites (IRESs). Cis-acting structural elements that lie within mRNAs and mediate cap-independent ribosome recruitment. Different IRES elements have varying requirements for translation initiation factors.

IRES-transactivating factors (ITAFs). Trans-acting protein cofactors that are required by some internal ribosome entry sites (IRESS), in addition to canonical translation initiation factors, in order to promote IRES-dependent translation initiation.

Polycistronic

Of an mRNA: containing

multiple ORFs or cistrons. In eukaryotes, most mRNAs are monocistronic, and specific cis-acting elements are

required to efficiently translate polycistronic mRNAs.

Polycistronic mRNAs, however, are relatively common in bacteria and archaea.
Targeting eIF4F directly. eIF4F can be inactivated or modified in infected cells. Proteases of enteroviruses, (including rhinoviruses), retroviruses and caliciviruses (including noroviruses) (TABLE 1) cleave eIF4G, severing the eIF4E-bound amino terminus from the eIF4A-eIF3-ribosome-associated carboxyl terminus. Although multiple eIF4G1 isoforms and eIF4G2 are cleaved by viral proteases in infected cells, inhibition of cap-dependent translation by poliovirus (an enterovirus) correlates with cleavage of eIF4G2 only, suggesting that different cellular mRNAs vary in their requirements for eIF4G family members ${ }^{17}$. Inhibiting host cap-dependent translation does not block viral mRNA translation, as many RNA viruses contain specialized internal ribosome entry sites (IRESs) (BOX 1) that direct cap-independent translation ${ }^{18}$. Although all IRESs recruit ribosomes independently of a cap, they differ in their requirements for initiation factors and ancillary IRES transactivating factors (ITAFs). DNA viruses, including simian virus 40 (SV40) and herpesviruses, also encode rare, IRES-containing polycistronic mRNAs ${ }^{19-21}$.

Targeting eIF4F binding partners. Instead of eIF4G proteolysis, the picornavirus encephalomyocarditis virus (EMCV) suppresses cap-dependent translation by activating the translational repressor 4EBP1 (REF. 22). Hypophosphorylated 4EBP1 binds eIF4E and prevents eIF4E binding to eIF4G, inhibiting eIF4F assembly. Precisely how EMCV activates 4EBP1 remains unclear, although vesicular stomatitis virus (VSV) M protein promotes hypophosphorylated 4EBP1 accumulation by inhibiting the kinase $\mathrm{AKT}^{23,24}$. Small $t$ antigens from murine polyomavirus and SV40 promote 4EBP1 hypophosphorylation via a poorly understood protein phosphatase 2A (PP2A)-dependent strategy ${ }^{25}$. Preventing 4EBP1 hyperphosphorylation helps viruses to suppress cap-dependent translation of host defence mRNAs, including interferon-regulatory factor 7 (IRF7), which regulates interferon production. Thus, replication of interferon-sensitive RNA viruses is suppressed in cells that are deficient in both 4EBP1 and $4 \mathrm{EBP} 2^{26}$. Other viruses (discussed below) that promote 4EBP1 hyperphosphorylation to stimulate eIF4F use different strategies to suppress translation of host defence-related mRNAs.

Influenza virus, VSV or adenovirus infection decreases the abundance of phosphorylated eIF4E, potentially helping to suppress host translation ${ }^{23,27,28}$. Although this process is not understood in influenza virus-infected cells, protein $100 \mathrm{~K}$ from adenoviruses binds eIF4G and displaces the eIF4E kinase MNK1, thus reducing the abundance of phosphorylated eIF4 $\mathrm{E}^{27}$. By binding late viral mRNA sequences in the $5^{\prime}$ tripartite leader, $100 \mathrm{~K}$ promotes 'ribosome shunting', enabling the $40 \mathrm{~S}$ ribosome, after loading onto a capped mRNA, to bypass large $5^{\prime}$ UTR segments and translocate to the initiation $\operatorname{codon}^{27,29}$. Complementarity between adenoviral mRNA and $18 \mathrm{~S}$ ribosomal RNA is important for shunting, suggesting a role for mRNA structure or mRNA-rRNA interactions ${ }^{30}$. Shunting also occurs on cauliflower mosaic virus (CaMV) 35S mRNA, but in this case it requires an upstream ORF (uORF) and specific mRNA structures ${ }^{31}$.

Viruses also target the eIF4F-associated PABP proteins. Besides binding $3^{\prime}$ terminal sequences of nonpolyadenylated viral mRNAs, rotavirus NSP3 interacts with eIF4G and displaces PABP to inhibit host translation $^{32}$. However, silencing NSP3 expression in infected cells does not detectably diminish viral-protein synthe$\operatorname{sis}^{33}$. In addition, enterovirus, lentivirus and calicivirus proteases cleave PABP, and the rubella virus capsid protein binds PABP to suppress translation ${ }^{17,32}$. Although PABP stimulates some IRESs, PABP inactivation by RNA viruses does not always correlate with host shut-off, but rather suppresses viral mRNA translation to foster positive-strand genome replication ${ }^{17,32}$.

Innate host defences may impair eIF4F function in infected cells through ISG15, an interferon-induced, ubiquitin-like modifier. The cap-binding activity of the eIF4E family member 4EHP (also known as eIF4E2) is enhanced by ISG15 conjugation ${ }^{34}$. 4EHP, however, cannot bind eIF4G and competes with eIF4E, suppressing capdependent translation. Although virus-induced suppression of interferon-stimulated gene expression limits ISG15 production, specific viral ISG15-4EHP conjugation antagonists, or the consequences of ISG15 conjugation to 4EHP in infected cells, remain unknown. 


\section{Table 1 | Viral functions and their impact on host translation factor targets}

\begin{tabular}{|c|c|c|c|}
\hline & Viruses & Viral functions & Effects on target \\
\hline \multirow[t]{2}{*}{ elF4E } & Caliciviruses and TMV & $\mathrm{VPg}$ & Binds elF4E and recruits factors to viral mRNA \\
\hline & Enteroviruses & Unknown & Induces host miR-141 and suppresses elF4E mRNA translation \\
\hline \multirow{7}{*}{ 4EBP1 } & Reoviruses & $\mathrm{p} 17$ & \\
\hline & SV40 & Small t antigen & Dephosphorylates 4EBP1 (PP2A dependent) \\
\hline & HCMV & UL38 & \\
\hline & KSHV & v-GPCR & Phosphorylate 4EBP1 (via PI3K-AKT-mTOR pathway activation) \\
\hline & EBV & LMP2A & \\
\hline & Adenoviruses & E4 ORF1 and E4 ORF4 & \\
\hline & $\mathrm{HCV}$ & NS5A & Phosphorylates 4EBP1 (via FKBP38 binding to activate mTOR) \\
\hline \multirow{7}{*}{ elF4G } & Retroviruses & Protease & \\
\hline & FMDV & Leader protease & \\
\hline & Influenza viruses & Polymerase NS1 & Binds elF4G and promotes viral-mRNA translation \\
\hline & Adenoviruses & $100 \mathrm{~K}$ & $\begin{array}{l}\text { Binds elF4G, dephosphorylates elF4E (via competitive displacement of MNK1) and } \\
\text { promotes ribosome shunting on viral mRNAs }\end{array}$ \\
\hline & Rotaviruses & NSP3 & Binds elF4G and competitively displaces PABP \\
\hline & HSV-1 & ICP6 & Binds elF4G and increases its interaction with elF4E \\
\hline & Enteroviruses & IRES & Interacts with eIF4G to recruit the $40 \mathrm{~S}$ ribosomal subunit \\
\hline \multirow{9}{*}{ РABP } & Lentiviruses & Protease & \\
\hline & Rubella virus & Capsid & Binds PABP and suppresses translation \\
\hline & Influenza viruses & NS1 & Binds PABP (consequence unknown) \\
\hline & HSV-1 & $\mathrm{ICP} 27$ & Binds PABP and stimulates translation of a viral mRNA subset \\
\hline & & ICP27 and UL47 & Cause nuclear PABP accumulation \\
\hline & HCMV & UL69 & Binds PABP (consequence unknown) \\
\hline & KSHV & SOX and K10 & Bind PABP and causes its nuclear accumulation \\
\hline & Bunyaviruses & NSS protein & Causes nuclear PABP accumulation \\
\hline & Rotaviruses & NSP3 & $\begin{array}{l}\text { Displaces PABP from elF4G, and interacts with ROXAN to cause nuclear PABP } \\
\text { accumulation }\end{array}$ \\
\hline \multirow[t]{7}{*}{ elF3 } & Measles virus & N protein & Binds elF3g and impairs translation \\
\hline & Rabies virus & M protein & Binds elF3h and impairs translation \\
\hline & SARS CoV and IBV & Spike protein & Binds elF3f and impairs translation \\
\hline & $\begin{array}{l}\text { Caliciviruses (including } \\
\text { noroviruses) }\end{array}$ & $\mathrm{VPg}$ & Binds elF3 and recruits factors to viral mRNA \\
\hline & CaMV & RISP & $\begin{array}{l}\text { Binds elF3a and elF3c, binds the } 60 \text { S ribosomal subunit L24 and recruits ribosomes for } \\
\text { re-initiation }\end{array}$ \\
\hline & & TAV & Binds and activates TOR, and recruits RISP \\
\hline & HCV, CSFV and HIV & IRES & Interacts with elF3 and recruits translation machinery \\
\hline
\end{tabular}


Table 1 (cont.) | Viral functions and their impact on host translation factor targets

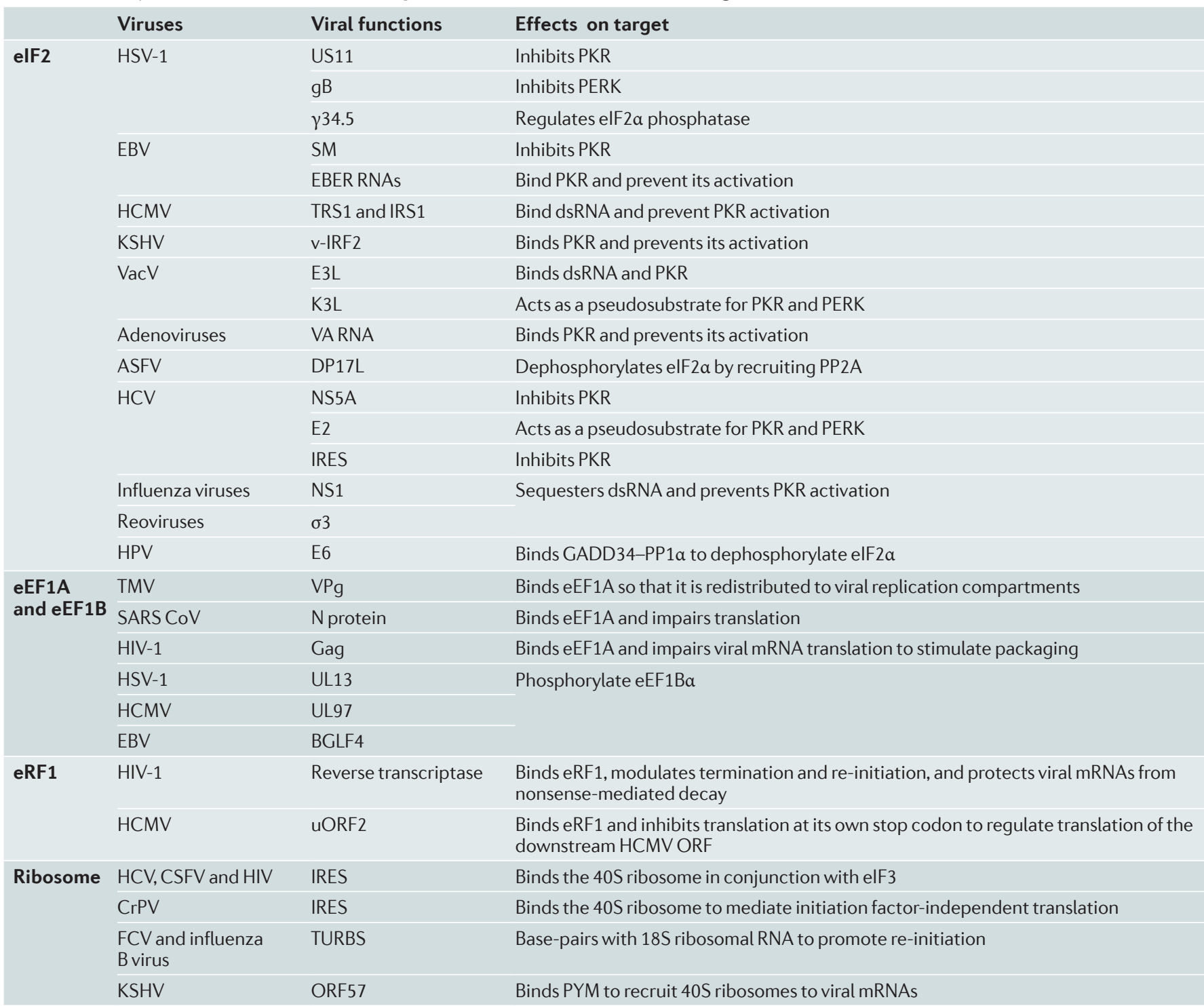

4EBP, elF4E-binding protein; ASFV, African swine fever virus; CaMV, cauliflower mosaic virus; CrPV, cricket paralysis virus; CSFV, classical swine fever virus; dsRNA, double-stranded RNA; EBV, Epstein-Barr virus; eEF, eukaryotic elongation factor; elF, eukaryotic translation initiation factor; eRF, eukaryotic release factor; FCV, feline calicivirus; FMDV, foot-and-mouth disease virus; GADD34, growth arrest and DNA damage-inducible protein 34; HCMV, human cytomegalovirus; HCV, hepatitis C virus; HPV, human papilloma virus; HSV, herpes simplex virus; IBV, infectious bronchitis viruses; IRES, internal ribosome entry site; KSHV, Kaposi's sarcoma-associated virus; miR-141, mature microRNA 141; mTORC, mTOR complex; PABP, poly(A)-binding protein; PDK1, phosphoinositide-dependent protein kinase 1; PI3K, phosphoinositide 3-kinase; PP 1 $\alpha$, protein phosphatase $1 \alpha$; PP2A, protein phosphatase 2A; RISP, re-initiation supporting protein; ROXAN, rotavirus ' $\mathrm{X}$ '-associated non-structural protein; SARS CoV, severe acute respiratory syndrome coronavirus; SV40, simian virus 40; TAV, transactivator viroplasmin; TMV, tobacco mosaic virus; TSC2, tuberin; TURBS, termination upstream ribosomal-binding site; uORF2, upstream ORF 2; VacV, vaccinia virus; v-GPCR, viral G protein-coupled receptor; vhs, virion host shut-off; VSV, vesicular stomatitis virus.

Stimulating eIF4F activity. In contrast to viruses that inhibit eIF4F and use cap-independent translation, many DNA viruses, the mRNAs from which are structurally similar to host mRNAs (with a $5^{\prime} \mathrm{m}^{7} \mathrm{G}$ cap and $3^{\prime}$ poly(A) tail) rely on cap-dependent translation and stimulate eIF4F activity. Herpesviruses (herpes simplex virus type 1 (HSV-1), human cytomegalomvirus (HCMV), EpsteinBarr virus (EBV) and Kaposi's sarcoma-associated herpesvirus (KSHV)), vaccinia virus (VacV) (a poxvirus) and asfarviruses all activate mTORC1, promoting 4EBP1 phosphorylation, eIF4F assembly, viral protein synthesis and viral replication ${ }^{25,35-41}$. Indeed, inhibitors of the mTOR active site (targeting both mTORC1 and mTORC2) suppress protein synthesis in infected cells and inhibit replication of a representative alphaherpesvirus (HSV-1), betaherpesvirus (HCMV) and gammaherpesvirus (murine herpesvirus 68 ) $^{42-44}$. In addition to promoting eIF4F assembly, 4EBP1 phosphorylation stimulates HSV-1 and HCMV replication, as a dominant 4EBP1 repressor with alanine substitutions at the Thr37 and Thr46 phosphorylation sites represses viral protein synthesis for these species ${ }^{44,45}$. To activate mTORC1 and stimulate 4EBP1 hyperphosphorylation, the HSV-1 Ser/Thr kinase US3 acts as an AKT surrogate 


\section{Box 1 | Internal ribosome entry sites}

There are four types of internal ribosome entry sites (IRESs) (see the figure), each of which can directly interact with host translational components and circumvent conventional cap-dependent ribosome recruitment ${ }^{18}$. These sites can confer a potent competitive advantage to viral mRNAs, freeing them from host regulatory constraints and, in cases for which viral infection impairs cap-dependent translation, sustaining viral protein synthesis. Type I (for example, poliovirus) and II (for example, encephalomyocarditis virus) IRESs were first identified in picornaviruses. These two IRES types interact with the eukaryotic translation initiation factor 4G (elF4G; labelled $4 G$ ) carboxy-terminal domain ${ }^{18}$, which binds to elF4A (labelled 4A) and elF3. They require elF5B, elF2 and initiator-methionine tRNA (Met-tRNA), and are stimulated by the activity of elF1, elF1A and elF4B. They also require IRES trans-acting factors (ITAFs), which are RNA-binding proteins that alter IRES conformation and can promote elF4G binding. Notably, the hepatitis A virus IRES is unusual in that it requires intact elF4F with the cap-binding slot of elF4E unoccupied, suggesting that elF4E interacts with the viral mRNA or induces the conformational changes in elF4G that are necessary for IRES binding. Type III IRESs, typified by those of hepatitis $C$ virus and the pestiviruses, bypass requirements for elF4F altogether by interacting with both elF 3 and the $40 \mathrm{~S}$ ribosome ${ }^{71}$, analogous to ribosome recruitment through Shine-Dalgarno sequences in bacteria. These IRESs also require elF5B, elF2 and Met-tRNA, although the requirement for these factors may be reduced in some cases (see main text). Finally, type IV IRESs of the family Dicistroviridae completely obviate the need for canonical initiation factors ${ }^{67,68}$. Remarkably, these IRESs interact with the 40 S subunit directly, inducing conformational changes and facilitating $60 \mathrm{~S}$ subunit joining to form $80 \mathrm{~S}$ ribosomes independently of initiation factors. In addition, a CCU sequence is positioned in the ribosomal $P$ site while the $A$ site is occupied by a CGU (encoding alanine). An initial 'pseudo-translocation' of the Ala-tRNA to the P-site initiates translation, resulting in viral precursor polypeptides with amino-terminal alanine residues rather than methionine.

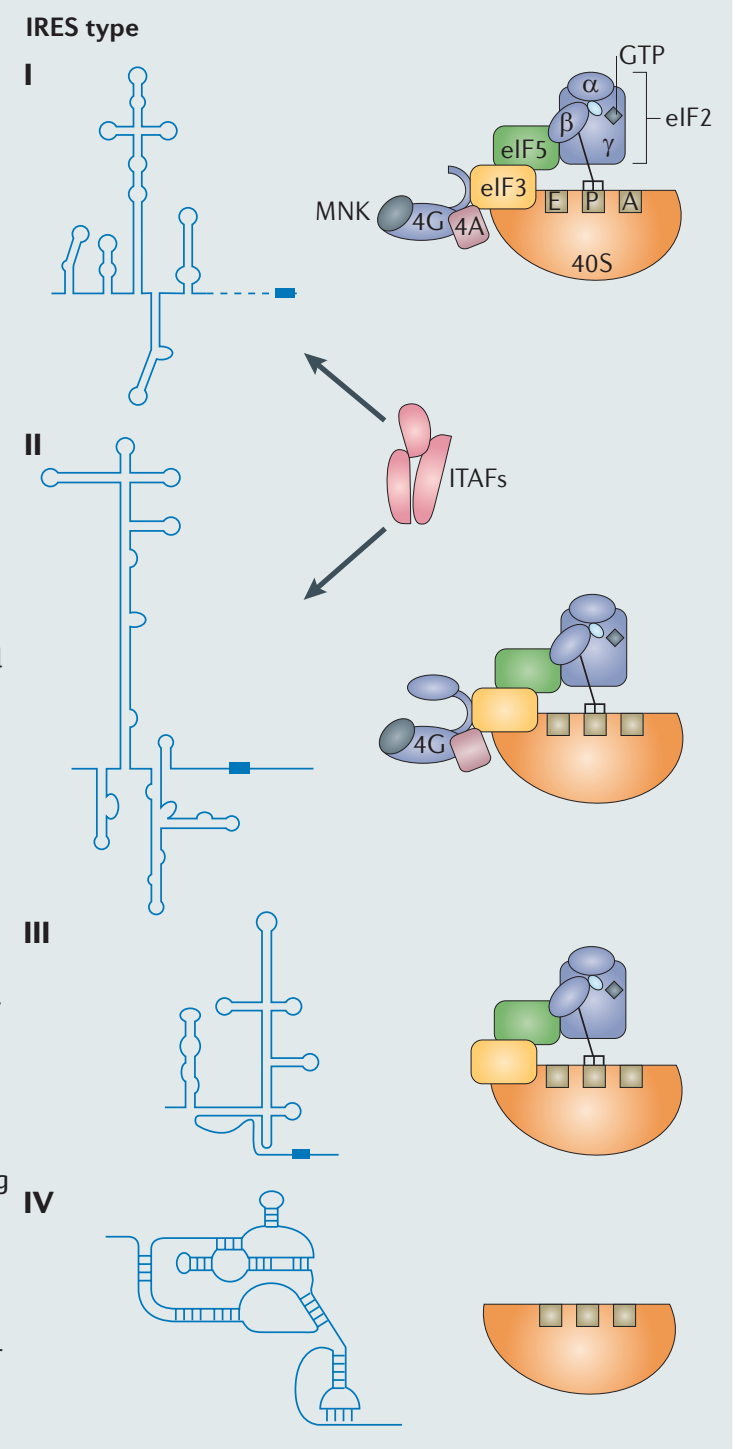

by phosphorylating tuberin (TSC2) ${ }^{44}$. HCMV UL38 also binds to TSC2 and thus inhibits the TSC complex to activate mTORC1 (REF. 46); in addition, the substrate specificity of mTOR-containing complexes is modified in HCMV-infected cells ${ }^{25,47}$. Although human papilloma virus (HPV) E6 and adenovirus E4 ORF1 activate mTORC1 either at or upstream of TSC, a second adenoviral function stimulates mTORC1 in a TSC-independent manner that may involve PP2A $\mathrm{A}^{25,48,49}$ (FIG. 2; TABLE 1). Although additional viruses stimulate phosphoinositide 3-kinase (PI3K)-AKT signalling, it is not clear whether this regulates translation in infected cells ${ }^{50}$. Finally, steady-state 4EBP1 levels decrease in HSV-1 and VacV-infected cells ${ }^{35,38,39,44}$, as 4EBP1 hyperphosphorylation can result in proteasome-mediated degradation. 4EBP1 degradation is not restricted to virus-infected cells and also occurs in uninfected cells ${ }^{51,52}$.

Simply inactivating 4EBP1 is not always sufficient for eIF4F assembly. In HSV-1-infected cells, eIF4E binding to eIF4G requires a virally encoded eIF4G-binding protein, ICP6 (also known as R1) ${ }^{53}$. ICP6 is multifunctional and is also a subunit of the viral ribonucleotide reductase. When associated with eIF4G, however, ICP6 stimulates eIF4E binding to eIF4G and drives eIF4F assembly. Strikingly, in cells infected with an ICP6-deficient virus, eIF4E is released from the repressor $4 \mathrm{EBP} 1$ but increased eIF4F assembly is not observed ${ }^{53}$. This identified a new step controlling eIF4F formation, in addition to 4EBP1 hyperphosphorylation, that may be required under stressful conditions such as viral infection. Indeed, ICP6 contains a segment related to small heat shock proteins that can remodel translation factor complexes $^{54}$. Although eIF4E binding to eIF4G is stimulated in HSV-1-infected cells, PABP binding to eIF4F is unchanged or reduced ${ }^{37,55}$, depending on cell type. However, PABP can stimulate the translation of a subset of viral mRNAs by interacting with ICP27 (REF. 56). Further studies on PABP function in HSV-1-infected cells will resolve these findings. 
Compared with HSV-1, HCMV has a protracted life cycle and does not impair host translation. eIF4F assembly and binding to PABP are stimulated in HCMVinfected cells. Furthermore, eIF4E, eIF4G, eIF4A and PABP steady-state levels increase, and for PABP proteins this involves a translational control mechanism ${ }^{37,45}$. Thus, whereas picornaviruses impair cap-dependent translation by reducing the abundance of full-length initiation factors, HCMV stimulates the cap-dependent translation machinery and increases initiation factor concentration. How this is achieved and its contribution to viral replication remain unknown. Nevertheless, raising the concentration of eIF4F subunits may potentiate complex assembly. Instead of increasing host initiation factor levels, mimiviruses - large ( $2 \mathrm{Mb}$ ) DNA viruses that infect Acanthamoeba spp. - are the only viruses known to encode putative translation factors, one of which is eIF4 $\mathrm{E}^{57}$. However, the capacity of mimiviral homologues to function in translation initiation and their contribution to protein synthesis in infected cells are unknown.

Redistributing eIF4F and PABP. Although their abundance remains constant, changes in the local concentration of translation factors probably regulate protein synthesis in poxvirus- or asfarvirus-infected cells. Both types of DNA virus replicate in specialized cytoplasmic compartments and promote eIF4F assembly ${ }^{38,41}$. Remarkably, eIF4E and eIF4G are redistributed and concentrated in viral replication compartments $\mathrm{s}^{38,41,58}$. Increasing the local concentration of initiation factors in discrete regions could favour eIF4F assembly and sequester factors from host mRNAs to suppress cellular translation. Similarly, tobacco mosaic virus (TMV)-encoded VPg binds eIF4E, concentrating eIF4E and eIF4G on membrane-associated replication sites ${ }^{59}$, whereas Sindbis virus, an RNA virus that replicates in the cytoplasm and employs cap-independent translation, recruits eIF3 and eEF2 to viral compartments but excludes eIF4G ${ }^{60}$.

Redistribution of eIF4F and PABP is not limited to concentration in replication compartments. For instance, eIF4E is redistributed to the nucleus by poliovirus $^{61}$, possibly helping to suppress host translation. PABP, which normally shuttles between nucleus and cytoplasm, accumulates in the nucleus in bunyavirus-, rotavirus-, HSV-1- and KSHV-infected cells ${ }^{32,40,55,62-65}$. Interestingly, these viruses impair host protein synthesis. HSV-1 and KSHV in particular promote eIF4F assembly without stimulating PABP binding to eIF4F ${ }^{37,40,55,63}$. By contrast, $\mathrm{PABP}$ does not accumulate in the nucleus but is recruited to eIF4F, and host protein synthesis proceeds unimpaired, in cells infected with the related herpesvirus $\mathrm{HCMV}^{37,45}$. PABP redistribution and exclusion from eIF4F might help to inhibit host translation in HSV-1and KSHV-infected cells. Whether HSV-1 and KSHV mRNAs have reduced dependence on PABP to initiate translation, despite being polyadenylated, is unknown.

Although eIF4E binding to eIF4G regulates initiation, eIF4F assembly can induce eIF4E phosphorylation by the eIF4G-associated eIF4E kinase MNK1. p38 and/ or ERK activation stimulates eIF4E phosphorylation in cells infected with herpesviruses (HSV-1 (REF. 35), $\mathrm{HCMV}^{37}$ and $\mathrm{KSHV}^{40}$ ), poxviruses ${ }^{38}$, asfarviruses ${ }^{41}$ and coronaviruses ${ }^{66}$. Furthermore, inhibition of MNK proteins impairs HSV- ${ }^{35}, \mathrm{HCMV}^{37}$ and $\mathrm{VacV}^{38}$ productive replication 100 - to 300 -fold, and suppresses $\mathrm{KSHV}$ reactivation ${ }^{40}$. VacV replication is similarly reduced in MNK1-deficient cells ${ }^{38}$. Although MNKdependent eIF4E phosphorylation is not absolutely required for protein synthesis and is poorly understood, it is associated with increased viral protein synthesis and viral replication in herpesvirus-, asfarvirus- and poxvirus-infected cells.

\section{Targeting $40 \mathrm{~S}$ binding through elF3}

Excluding the mRNAs of cricket paralysis virus (CrPV), which dispense with initiation factors ${ }^{67,68}$, most viral mRNAs recruit 40 S subunits directly or indirectly through eIF3, irrespective of their requirement for eIF4F or their use of cap-dependent versus cap-independent mechanisms. In fact, viruses that rely on cap-independent translation to circumvent eIF4F often target eIF3 and ribosomal proteins. eIF3 is an adaptor that orchestrates how ribosomes, eIF4F and mRNA communicate, and is composed of 13 subunits (eIF3a-eIF3m) that interact (via eIF3e) with eIF4G, bind mRNA and contact the 40 S ribosome. eIF3j is intimately involved with ribosome function and occupies the ribosomal decoding centre to facilitate scanning and AUG selection with eIF1 ${ }^{1,69}$. Some viruses directly recruit eIF3 to viral mRNAs through cis-acting RNA elements or interactions with viral proteins that partially mimic eIF4F (FIG. 2; TABLE 1). eIF3 also functions in re-initiation following termination of uORF translation in polycistronic mRNAs ${ }^{70}$. Finally, eIF3 is targeted both by viruses seeking to inhibit host protein synthesis and by host defences attempting to impair viral protein production.

Recruiting eIF3 to viral $m R N A$. The VPg protein that is covalently linked to the $5^{\prime}$ end of the feline calicivirus (FCV) and human norovirus (HNV) positive-strand RNA genome, in place of a cap, recruits ribosomes by interacting with eIF3 (REF. 11). Other viruses (hepatitis C virus (HCV), classical swine fever virus (CSFV), HIV and potentially Sindbis virus) use IRESs to replace eIF4F function and directly bind eIF3 and 40S subunits ${ }^{69,71-73}$ (BOX 1). Substantial conformational changes in $40 \mathrm{~S}$ subunits occur on binding HCV and CrPV IRESs ${ }^{69}$, and 40 S binding similarly alters IRES conformation ${ }^{74}$. Small ribosome subunit protein RPS25 is essential for initiation from the CrPV IRES ${ }^{75}$, which directly binds 40 S subunits independently of eIF3 (REFS 67,68). RPS25 is also required for HCV IRES-directed initiation but has minimal effects on cellular protein synthesis, demonstrating that a ribosomal protein is selectively required for IRES-mediated translation ${ }^{75}$. This raises the possibility that other ribosomal proteins influence translation of non-IRES-containing mRNAs.

eIF3 also contributes to termination and re-initiation events on downstream ORFs of polycistronic viral mRNAs. Re-initiation on CaMV polycistronic mRNA requires the viral protein transactivator viroplasmin 
(TAV), which binds to the same eIF3g site as eIF4B and interacts with the plant protein re-initiation supporting protein (RISP). By binding eIF3a, eIF3c and ribosomal protein L24, RISP tethers TAV with 60 S and eIF3-bound $40 \mathrm{~S}$ subunits. TAV also recruits TOR to phosphorylate RISP, promoting re-initiation and viral replication ${ }^{76}$. FCV, however, uses an 87-nucleotide RNA cis-element to support eIF4F-independent re-initiation of eIF3-bound $40 \mathrm{~S}$ ribosomes on viral subgenomic polycistronic mRNA ${ }^{31}$.

Interfering with eIF3 via viral proteins and host antiviral functions can suppress protein synthesis in cells infected with RNA viruses. eIF3-binding proteins from measles virus and rabies virus inhibit host protein synthesis ${ }^{77,78}$, whereas foot-and-mouth disease virus protease degrades eIF3a and eIF3b subunits ${ }^{79}$. How viral $\mathrm{mRNAs}$ recruit ribosomes using modified eIF3 is not understood. Host antiviral defences also target eIF3. Interferon-stimulated gene products ISG54K (also known as IFIT2) and ISG56K are induced by interferon, dsRNA or infection with VSV, EMCV or Sendai virus. By binding eIF3e and eIF3c, ISG56K and ISGP54K block translation by antagonizing eIF2-GTP-Met-tRNA load- $_{\mathrm{i}}$ ing and ribosome association with eIF4F and mRNA ${ }^{80}$. How cellular eIF3-inhibitory functions are controlled once they are produced is not known.

\section{Targeting tRNA $A_{i}$ loading via elF2}

Even before recruitment to mRNA, the 40S ribosome is preloaded with Met-tRNA. This requires delivery of a ternary complex involving eIF2, GTP and Met-tRNA (FIG. 3). Importantly, the process of ternary-complex formation and $40 \mathrm{~S}$ loading is targeted by an innate host response designed to globally inhibit protein synthesis in virus-infected cells. eIF2 is a heterotrimeric guaninenucleotide-binding $(G)$ protein composed of a regulatory $\alpha$-subunit, a tRNA-binding $\beta$-subunit and a GTP-binding $\gamma$-subunit. Following eIF2.GDP release on AUG recognition and 60S subunit joining, GDP is exchanged for GTP by eIF2B to recycle active eIF2.GTP for another initiation round. eIF2 is inactivated by phosphorylation of its $\alpha$-subunit on Ser51 by any of four cellular kinases, each of which is activated by a discrete stress. GCN2 (also known as eIF2 $\alpha \mathrm{K} 4$ ) responds to amino acid starvation or ultraviolet light, haem deprivation activates HRI (also known as eIF $2 \alpha \mathrm{K} 1$ ), exceeding the protein-folding capacity of the endoplasmic reticulum triggers PERK (also known as eIF2 $\alpha \mathrm{K} 3$ ) and double-stranded (ds) RNA produced in virus-infected cells activates PKR (also known as eIF2 $\alpha$ K2). Phosphorylated eIF2 $\alpha$ has a greater affinity than its unphosphorylated counterpart for eIF2B and inhibits eIF2B guanine nucleotide exchange activity, thus depleting eIF2.GTP pools and inhibiting initiation $^{81}$. Because eIF2B is present in limiting quantities, small changes in eIF2 $\alpha$ phosphorylation have large effects on protein synthesis. Although activation of any eIF2 kinase in virus-infected cells could inhibit protein synthesis and potentially result in autophagy ${ }^{82}$, type I interferon production by virus-infected cells stimulates PKR accumulation in neighbouring cells. PKR activation following infection of interferon-primed neighbouring cells globally inhibits protein synthesis and curtails viral spread, making this activation a key player in the innate response to viruses ${ }^{1,81}$. However, host efforts to inactivate eIF2 by phosphorylation in order to limit viral replication are matched by viral countermeasures to inhibit interferon production and therefore indirectly prevent PKR accumulation, to directly preserve eIF2 activity for viral protein production or to bypass eIF2 function entirely (FIG. 3).

Preserving eIF2. To directly target $\mathrm{PKR}$, viruses encode dsRNA decoys that bind, but do not activate, PKR (such as the adenoviral VA RNA and the EBV EBERs), and PKR pseudosubstrates that divert activity from eIF2 (REF. 81). Other strategies include viral dsRNA-binding proteins that mask dsRNA and/or interact with and inhibit PKR (FIG. 3; TABLE 1), and phosphatase-regulatory subunits that bind cellular catalytic subunits to dephosphorylate eIF2 $\alpha$ (such as African swine fever virus (ASFV) DP71L $L^{83}$ and HSV $\gamma 34.5$ (also known as ICP34.5) ${ }^{84}$ ). By targeting phosphorylated eIF $2 \alpha$, phosphatases can antagonize any eIF2 $\alpha$ kinase. Often, viruses harness multiple strategies to prevent eIF2 phosphorylation, combining eIF2 $\alpha$-kinase-specific antagonists with a second function that broadly prevents phosphorylated-eIF $2 \alpha$ accumulation. For example, HSV-1 US11 binds dsRNA and PKR to inhibit the kinase while the HSV-1-encoded eIF2 $\alpha$ phosphatase subunit, $\gamma 34.5$, removes phosphate that reaches eIF $2 \alpha^{85}$. As a third method, HSV-1 glycoprotein $\mathrm{B}(\mathrm{gB})$ counteracts another eIF2 $\alpha$ kinase, PERK, preventing endoplasmic reticulum-stress-induced eIF2a phosphorylation ${ }^{86}$. Similarly, VacV encodes both a dsRNA-binding PKR inhibitor (E3L) and a PKR and PERK pseudosubstrate (K3L) ${ }^{87}$. Although the eIF2 $\alpha$ kinase GCN2 has antiviral effects ${ }^{88}$, GCN2-specific antagonists have not been reported. Finally, the protein kinase-inhibiting molecular chaperone P58 ${ }^{\mathrm{IPK}}$ (also known as DNAJ3K) limits eIF2 $\alpha$ phosphorylation in influenza virus-, TMV- and tobacco etch virus-infected cells, illustrating the fact that viruses conscript host factors to prevent eIF2 $\alpha$ phosphorylation ${ }^{89,90}$.

Inactivating eIF2. Some viruses benefit from eIF2 inactivation. $\mathrm{HCV}^{91}$, Sindbis virus ${ }^{92}$, pestiviruses ${ }^{93}$, reoviruses ${ }^{94}$ (including rotaviruses ${ }^{95}$ ), Semliki Forest virus $(\mathrm{SFV})^{96}$, poliovirus ${ }^{97}$ and $\mathrm{CrPV}^{98}$ induce eIF2 $\alpha$ phosphorylation. Although eIF2 $\alpha$ phosphorylation is not strictly required by rotaviruses or SFV, it helps to inhibit host translation. How viral mRNAs are translated without eIF2 or in the presence of phosphorylated eIF2 is beginning to emerge. Surprisingly, the CrPV IRES initiates translation without eIFs or Met-tRNA and only requires an $80 \mathrm{~S}$ ribosome and $\mathrm{eEFs}^{67,68}$. Sindbis virus late mRNAs are also insensitive to eIF $2 \alpha$ phosphorylation ${ }^{92}$, whereas CSFV employs both eIF2-dependent and eIF2-independent translation modes $^{18,99}$. Finally, PKR-mediated eIF2 $\alpha$ phosphorylation blocks interferon-induced protein production in HCV-infected cells ${ }^{91}$. Paradoxically, HCV proteins E2 and NS5A, as well as the HCV IRES, inhibit PKR and, in the case of E2, PERK ${ }^{81}$. Perhaps the HCV IRES is eIF2 independent in the physiological, infected-cell system. 
Indeed, high magnesium concentrations support HCV IRES function without eIF2 in vitro ${ }^{100}$. Alternatively, the HCV IRES could require eIF2, provided that HCV prevents eIF2 phosphorylation in local replication compartments on intracellular membranes but allows activated PKR to phosphorylate eIF2 in the cytoplasm. Cellular

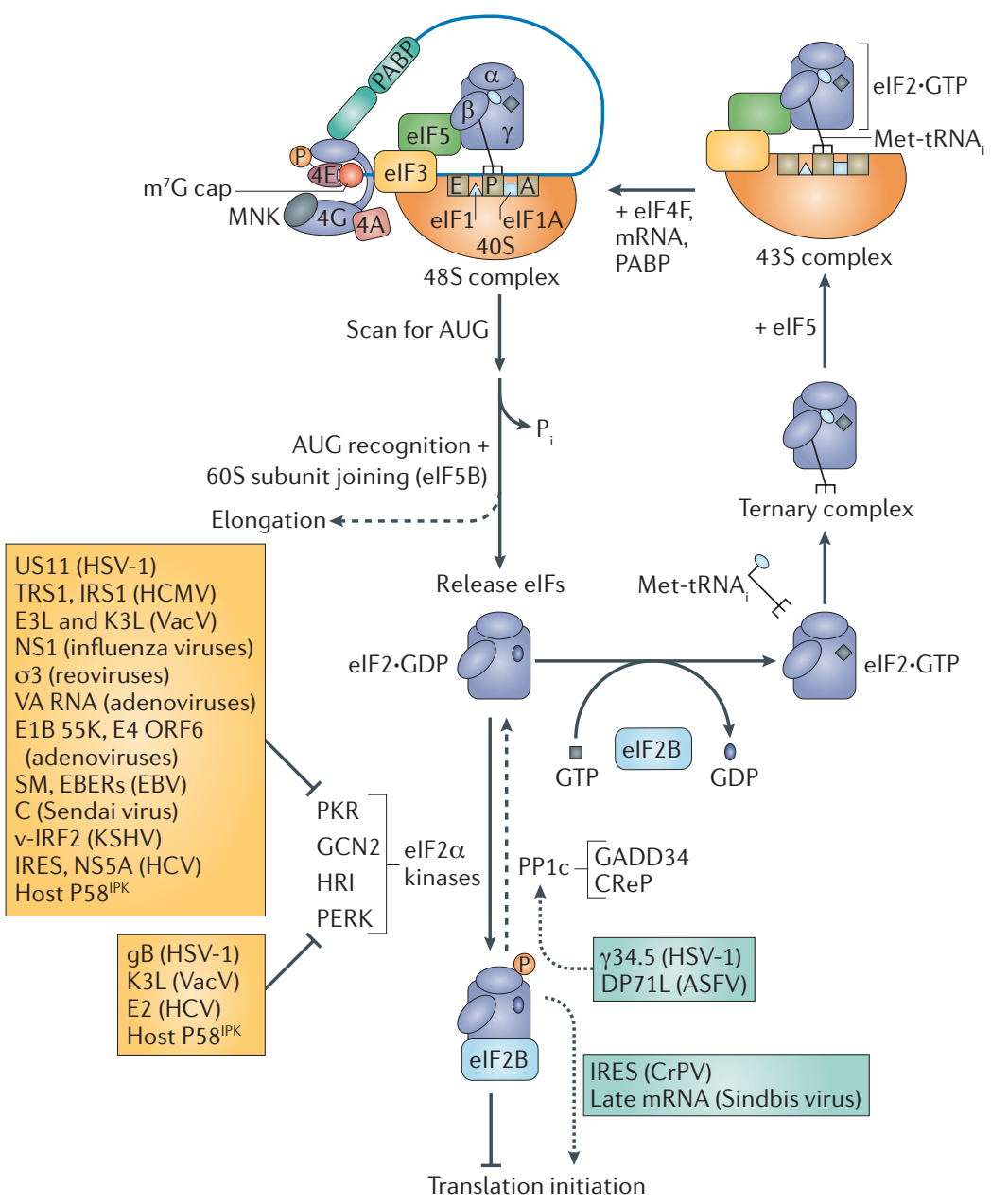

Figure 3 | Eukaryotic translation initiation factor 2-dependent loading of $40 \mathrm{~S}$ ribosomes with initiator tRNA regulates translation and is targeted by host antiviral defences. Inactive eukaryotic translation initiation factor 2 (elF2; with $\alpha$-, $\beta$ - and $\gamma$-subunits depicted) bound to GDP (elF2.GDP) is recycled to the active GTP-bound form by the five-subunit guanine nucleotide exchange factor elF2B. Once recycled, elF2.GTP forms a ternary complex with initiator-methionine tRNA (Met-tRNA) and is loaded onto the $40 \mathrm{~S}$ ribosome (see FIG. 1). A 43 S pre-initiation complex assembles after the ternary complex loads Met-tRNA into the ribosomal $P$ site, and this converts to a $48 \mathrm{~S}$ complex on recruitment to elF4F-and poly(A)-binding protein (PABP)-bound mRNA. Following identification of the AUG start codon by scanning, the GTPase-activating protein elF5 stimulates GTP hydrolysis, and 605 subunit joining triggers the release of elF2.GDP and inorganic phosphate $\left(\mathrm{P}_{\mathrm{i}}\right)$. The resulting $80 \mathrm{~S}$ ribosome carries out the elongation phase (FIG. 1). Phosphorylation of elF2 on its $\alpha$-subunit by one of four different cellular elF2 $a$ kinases (see main text for details), each of which is activated by a discrete stress, prevents eIF2 recycling. Phosphorylated eIF2 binds tightly to and inhibits eIF2B, blocking translation initiation. The host protein phosphatase 1 catalytic (PP1c) subunits can dephosphorylate elF2 when partnered with either an inducible (growth arrest and DNA damage-inducible protein 34 (GADD34)) or constitutively active (CReP; also known as PPP1R15B) regulatory component. Viral strategies for inhibiting elF2 $a$ phosphorylation (yellow), activating elF2a dephosphorylation (green) or bypassing a requirement for elF2 (green) are indicated. See main text for details and abbreviatons; elF4A, elF4E and elF4G are labelled 4A, 4E and 4G, respectively. factors - including ligatin (also known as the GTPindependent initiation factor eIF2D ${ }^{101}$ ) and MCT1 (also known as MCTS1)-DENR (also known as DRP) $)^{73}-$ that are capable of recruiting Met-tRNA to $40 \mathrm{~S}$ subunits and positioning the AUG start codon directly into the P site may explain the eIF2-independent initiation mechanisms used by HCV and Sindbis virus IRESs.

\section{Targeting elongation and termination}

Whereas translation initiation is rate limiting and involves numerous factors that are each subjected to intricate regulation, the processes of elongation and termination require a more limited set of factors, but viruses can nonetheless effectively target these factors. Increased elongation rates are required to cope with elevated initiation rates. Thus, viruses that activate mTORC1 to promote initiation also stimulate $\mathrm{p} 70$ ribosomal protein S6 kinase (p70 S6K) proteins, which phosphorylates and inhibits eEF2 kinase (FICS 1,4). As eEF2 phosphorylation by eEF2 kinase inhibits elongation, p70 S6K stimulates elongation. By contrast, eEF2 kinase is stimulated by protein kinase $\mathrm{A}$ (PKA), $\mathrm{Ca}^{2+}$-calmodulin or AMP-activated protein kinase (AMPK), thus reducing elongation ${ }^{2}$. Viruses can alter eEF function and subcellular distribution. Similarly, viral manipulation of termination factors can regulate polyprotein synthesis or couple termination to re-initiation.

Elongation. eIF5B has a key role in transitioning from initiation to elongation by promoting initiation factor displacement and $60 \mathrm{~S}$ subunit joining ${ }^{1}$. To control $60 \mathrm{~S}$ recruitment and elongation, eIF5B, eEF1A and eEF2 are respectively inactivated by enterovirus 3C protease, severe acute respiratory syndrome (SARS) coronavirus (SARS CoV) N protein and avian reovirus p17 (REFS 102-104). Although these probably contribute to host shut-off, how viral mRNA translation proceeds without intact eIF5B or functional eEFs remains unknown. By interacting with eEF1A, HIV Gag inhibits viral mRNA translation and stimulates RNA packaging into virions ${ }^{105}$. As an alternative method, TMV VPg binds to eEF1A and causes it to accumulate on intracellular membranes, where viral replication occurs ${ }^{59}$. Similarly, eEF2 is recruited to cytoplasmic viral replication compartments in cells infected with Sindbis virus ${ }^{60}$ or $\mathrm{ASFV}^{41}$. Finally, the eEF1Ba subunit (formerly known as eEF1 $\delta$ ), which mediates GDP-GTP exchange on eEF1A, is hyperphosphorylated by a conserved herpesvirus kinase $\mathrm{e}^{106}$, although how this affects translational control in infected cells is unknown.

Termination. On stop codon recognition by eRF1, the completed polypeptide is released and the GTPase eRF3 removes eRF1 from the ribosome ${ }^{3}$ (FIG. 5). Termination and re-initiation may be linked through the interaction of PABP with ribosome-bound eRF3 and cap-bound eIF4F $\mathrm{F}^{32,107}$. Polycistronic mRNAs of RNA viruses, for example, employ coupled termination-re-initiation events to translate downstream ORFs, similarly to bacteriophage translational coupling (BOX 2). Murine norovirus VP2 is synthesized by such coupling ${ }^{108}$. 


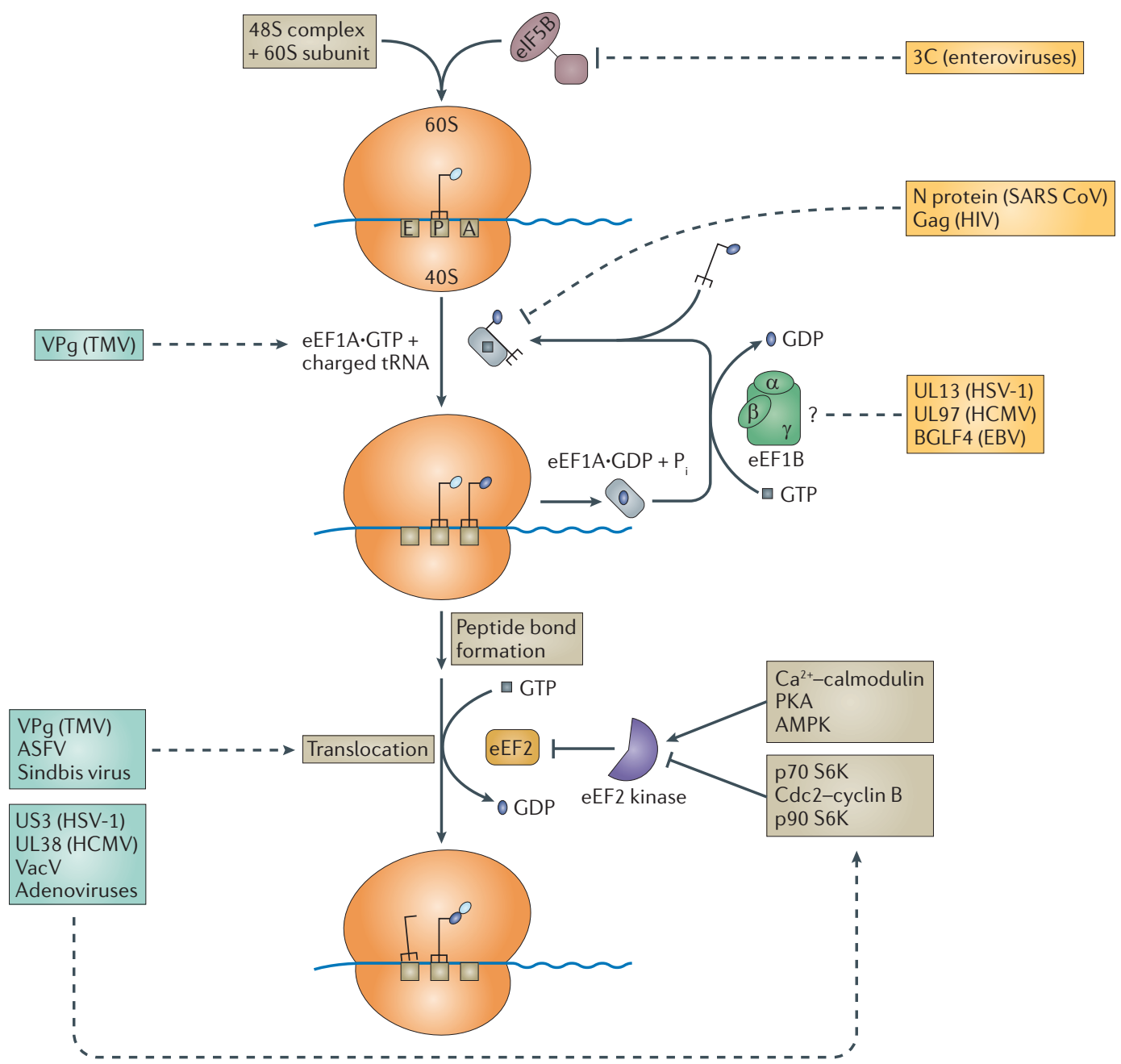

Figure 4 | Regulation of translation elongation. Although most translational control strategies operate at the rate-limiting initiation step, different regulatory mechanisms target elongation and termination. Translation elongation begins after eukaryotic translation initiation factor $5 \mathrm{~B}$ (elF5B)-mediated $60 \mathrm{~S}$ subunit joining triggers elF release, and the assembled $80 \mathrm{~S}$ ribosome begins polypeptide chain extension. Each new aminoacylated tRNA is delivered to the A site by eukaryotic elongation factor 1A (eEF1A) bound to GTP. Following GTP hydrolysis, eEF1A.GDP is released, unable to bind aminoacylated tRNA until it is recycled to the active GTP-bound form by the multisubunit eEF1B guanine nucleotide exchange factor. Both eEF1A and eEF1B can be phosphorylated by cellular kinases, including CK2 and protein kinase C, which stimulate their activity. Ribosome-catalysed peptide bond formation precedes eEF2-mediated translocation of the peptidyl-tRNA into the $P$ site and the de-acylated tRNA into the $E$ site, exposing the unoccupied $A$ site for successive rounds of elongation that form the polypeptide chain. eEF2.GDP exits the ribosome and is recycled to the active, GTP-bound form without the assistance of a guanine nucleotide exchange factor, owing to the high intrinsic GDP release rate. Phosphorylation by eEF2 kinase inhibits eEF2 activity. eEF2 kinase itself is phosphorylated and inhibited by p70 ribosomal protein S6 kinase (p70 S6K) proteins following mTOR complex 1 activation. By contrast, eEF2 kinase is activated by protein kinase $\mathrm{A}(\mathrm{PKA}), \mathrm{Ca}^{2+}$-calmodulin and $\mathrm{AMP}$-activated protein kinase (AMPK) ${ }^{2}$. Viral functions that regulate elongation are indicated; see main text for details and abbreviations. $\mathrm{Pi}$, inorganic phosphate.

A termination upstream ribosomal-binding site (TURBS) cis-element in FCV (70 nucleotides) and influenza B virus (45 nucleotides) positions the ribosome for re-initiation by base-pairing with $18 \mathrm{~S}$ rRNA to allow translation of the FCV and influenza virus ORFs encoding VP2 and BM2 (also known as M) ${ }^{109,110}$, respectively. Retroviral reverse transcriptase binds eRF1 to modulate termination and re-initiation ${ }^{111}$, and re-initiation protects HIV-1 mRNAs from nonsense-mediated decay ${ }^{112}$. Finally, termination in small uORFs can have a regulatory role by restricting scanning ribosomes from re-initiating at downstream cistrons. A variation of this strategy operates in HCMV-infected cells, in which ribosomal stalling (which is dependent on the sequence of the uORF2 peptide) prevents scanning ribosomes from reaching the downstream UL4 ORF. By binding eRF1, uORF2 peptide inhibits translation at its own stop codon. Ultimately, the stalled ribosome disengages the mRNA ${ }^{113}$.

\section{Exploiting mRNA metabolism}

Competition between virus and host for limiting translation components is influenced by mRNA availability in 


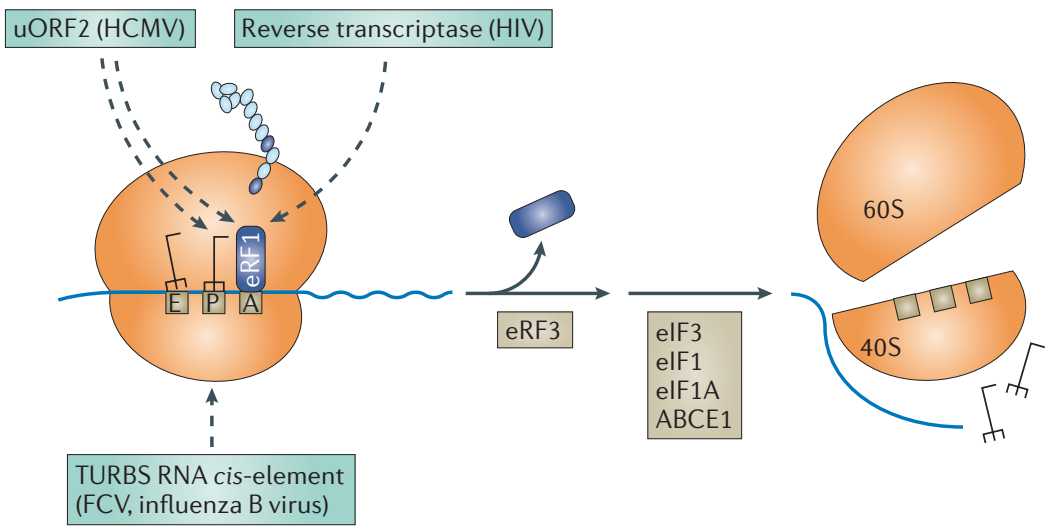

Figure 5 | Regulation of translation termination in virus-infected cells. On recognition of a stop codon in the A site, eukaryotic release factor 1 (eRF1) triggers $80 \mathrm{~S}$ arrest and polypeptide release. eRF3 subsequently releases eRF1 from the ribosome, and the $80 \mathrm{~S}$ ribosome is dismantled into $40 \mathrm{~S}$ and $60 \mathrm{~S}$ subunits (see FIG. 1). Virally encoded functions that regulate termination are indicated. Notably, HIV reverse transcriptase and the termination upstream ribosomal-binding site (TURBS) RNA cis-elements in influenza B virus and feline calicivirus (FCV) allow eukaryotic ribosomes to efficiently re-initiate translation, a property normally associated with prokaryotic ribosomes. elF, eukaryotic translation initiation factor; HCMV, human cytomegalovirus; uORF2, upstream ORF 2. shut-off (vhs) and a conserved function encoded by related gammaherpesviruses (KSHV SOX, murine herpesvirus 68 muSOX and EBV BGLF5) accelerate mRNA turnover to help suppress host protein synthesis ${ }^{64,120}$. Instead of a ribonuclease, poxviral decapping enzymes remove $m^{7} \mathrm{G}$ caps from mRNAs, converting them into substrates for host mRNA decay pathways and contributing to host shut-off ${ }^{4}$. Thus, although HSV-1, KSHV and VacV stimulate eIF4F activity and assembly (as discussed above), their global assault on mRNA metabolism ensures that predominately viral mRNAs accumulate in the cytoplasm and are translated. Finally, host defences harness a powerful RNA decay pathway involving RNase $\mathrm{L}$, which attacks mRNA and rRNA. To preserve cellular rRNA and viral mRNA, viruses often encode functions that antagonize RNase $\mathrm{L}$ activation, many of which also prevent PKR activation ${ }^{81}$.

Viral infection alters the distribution and composition of stress granules and processing bodies (P-bodies), which are discrete cytoplasmic structures associated with mRNA metabolism ${ }^{96}$. Stress granules contain translationally inactive mRNAs and accumulate in response to translation inhibition, including that mediated by eIF $2 \alpha$ phosphorylation and eIF4G cleavage, whereas P-bodies are associated with mRNA degradation. Poliovirus in particular degrades factors involved in P-body formation (poly(A)-nuclease and the exonuclease XRN1) and induces formation of modified stress granules that lack G3BP, which is cleaved by the viral $3 \mathrm{C}$ protease ${ }^{121-123}$. Although the function of modified stress granules in infected cells remains unclear, inactivating P-body components might protect viral mRNAs, which are uncapped, from degradation. Other RNA viruses (rotaviruses and $\mathrm{CrPV}$ ) block the formation of stress granules and, in the case of CrPV, P-bodies, despite inducing eIF2 $\alpha$ phosphorylation ${ }^{95,124}$. By contrast, stress granule induction by reoviruses may inhibit host translation ${ }^{125}$. Although stress granule components can stimulate replication of some RNA viruses (respiratory syncytial virus, dengue virus and West Nile virus) ${ }^{126}$, other viruses exploit P-bodies for viral assembly (HIV-1 and brome mosaic virus) ${ }^{96,127}$ or cap stealing (hantaviruses $)^{7}$. DNA viruses can also target stress granules, as the PKR antagonist encoded by VacV, E3L, prevents their accumulation ${ }^{128}$.

\section{MicroRNAs}

Small, non-coding microRNAs (miRNAs) can regulate the stability and translation of both host and viral mRNAs via RNA interference (RNAi). After processing from a larger, primary transcript, a 22-nucleotide miRNA is loaded into the RNA-induced silencing complex (RISC). Perfect base pairing with target sequences commonly found in the $3^{\prime}$ UTR triggers mRNA degradation, whereas imperfect base pairing inhibits translation $^{129}$. Although RNAi is a potent host antiviral defence mechanism in plants and invertebrates, virally encoded functions can antagonize the host miRNA machinery. Whether miRNAs contribute to mammalian innate antiviral responses remains less clear. However, herpesviruses in particular do express virally encoded miRNAs 


\section{Box 2 | Lessons in translation from bacteriophages}

Differences in the physical structure, ORF organization, ribosome composition and initiation factors for bacterial mRNAs compared with eukaryotic mRNAs influence bacteriophage translation strategies ${ }^{145}$. Besides having smaller, $70 \mathrm{~S}$ ribosomes and uncapped, predominately genome-collinear, non-polyadenylated mRNAs, bacteria mediate $30 \mathrm{~S}$ ribosome recruitment without scanning, through $16 \mathrm{~S}$ ribosomal RNA base-pairing with a Shine-Dalgarno (SD) cis-element proximal to the AUG start codon. Ribosomes also re-initiate translation efficiently in bacteria, enabling the translation of polycistronic mRNAs.

To regulate ribosome recruitment, phage RNA-binding proteins (RNA-BPs) recognize targets near $\mathrm{SD}$ sites, thus occluding ribosome binding to the translation initiation region (tir). This allows RNA replicases and coat proteins to suppress translation, fostering genome replication and RNA packaging, respectively. Phage T4 proteins involved in DNA replication autogenously repress translation of their own encoding mRNA by sequence-specific or, in the case of gp32 (which binds single-stranded DNA), cooperative structure-specific binding. Restricting the repressor activity of gp32 to unbound monomers that are superfluous for DNA replication serves as a rheostat, limiting $9 \mathrm{p} 32$ accumulation ${ }^{146}$. Similarly, translation repression by free, unassembled phage P22 gene 8 scaffold protein maintains the scaffold-to-coat protein ratio that is required for phage assembly ${ }^{147}$. tir-binding proteins also remodel repressive RNA structures to stimulate translation, as phage Mu Com promotes the synthesis of DNA-modification enzyme Mom ${ }^{148}$.

Modifications of the mRNA structure also regulate phage mRNA translation. Processing of phage T7 1.1 and 1.2 gene mRNAs by host RNase III stimulates translation ${ }^{149}$.

However, cleavage of the SD sequence of phage T4 early mRNA by an endoribonuclease comprising phage T4 RegB and host ribosomal protein S1 limits the accumulation of early proteins, stimulating translation of middle and late mRNAs ${ }^{146}$. Transit through an upstream cistron by translating ribosomes can modify the higher-order structure of a polycistronic transcript, regulating initiation for the downstream cistron by controlling SD exposure ${ }^{150}$. Such 'translational coupling' requires ribosome release factors when translation of a downstream cistron involves an upstream ribosome that must terminate before re-initiating (compared with entry of a new ribosome) ${ }^{151}$.

Besides coupling, other methods of maintaining subunit stoichiometry are recoding and bypassing. These processes also maximize coding capacity by altering ribosome decoding of a contiguous ORF. Recoding via programmed frameshifting regulates protein levels or allows overlapping ORFs to produce fixed protein ratios, as in phage $\lambda$, phage HK97 and phage Mu tail assembly genes ${ }^{152}$. Bypassing joins the information in two ORFs into one polypeptide. Using a peptidyl-tRNA decoding mechanism, signals in the phage T4 gene 60 mRNA stimulate ribosome take-off, mRNA slippage without scanning, and ribosome landing, bypassing 50 nucleotides between two ORFs ${ }^{153}$.

Translation control provides a powerful physiological sensor that regulates the lytic phase-lysogenic phase developmental decision in temperate phages. Phage $\lambda$ lysogeny requires synthesis of the repressor $\mathrm{Cl}$, which is positively regulated by $\mathrm{Cll}$ and $\mathrm{CIII}$. Translation of both CII and CIII mRNA is stimulated by host proteins binding near the $5^{\prime}$ end of the $\mathrm{mRNA}^{154}$. Translation of phage $\lambda N$ mRNA, encoding a transcription elongation factor required for lytic replication, is also autogenously repressed by $\mathrm{N}$ protein binding to the $5^{\prime}$ untranlsated region. Subsequent RNase III-mediated cleavage removes the $\mathrm{N}$-binding site, stimulating $\mathrm{N}$ synthesis and phage $\lambda$ replication ${ }^{155}$. Even more elaborate systems are found in phage $\mathrm{P} 1$ and phage $\mathrm{P} 7$, in which prophage C4 antisense RNAs indirectly antagonize the synthesis of anti-repressor by combining translational repression and coupling to regulate transcription ${ }^{156}$.

Bacterial antiviral responses also exploit the translation control mechanisms of phages. The Orf1 protein of phage bIL66 activates translation of $M$ operon mRNA by binding to an RNA structural element. A similar motif in the AbiD1 gene of the host, Lactococcus lactis, confers Orf1 responsiveness and results in an abortive infection ${ }^{157}$.

in latently infected cells, and these miRNAs are thought to suppress expression of lytic genes and help maintain latency. They also suppress host apoptotic and immune responses. Another DNA virus-encoded miRNA reduces translation of the SV40 large T antigen mRNA to limit the host immune response ${ }^{129}$. Poxviruses and most RNA viruses have not been reported to encode miRNAs. This may reflect their cytoplasmic replication, which could restrict access to nuclear miRNA-processing steps, or, for some RNA viruses, may reflect the potentially detrimental effects of miRNA processing on viral genome integrity. RNA viruses can, however, use miRNA-based strategies to manipulate the host translation machinery. Induction of a host transcription factor in enterovirusinfected cells promotes miR-141 expression, which impairs translation of eIF4E-encoding mRNA and inhibits cap-dependent protein synthesis ${ }^{130}$. The HCV RNA genome 5' UTR contains two tandemly repeated, liver-specific miR-122 targets. Surprisingly, miR-122 enhances, rather than suppresses, both genome abundance $^{131}$ and viral mRNA translation ${ }^{132,133}$, possibly through effects on the conformation of the HCV IRES. These target sites destabilize reporter mRNAs when placed in the $3^{\prime}$ UTR, suggesting that the functional outcome of miRNAs on their targets is influenced by the position of their recognition sites ${ }^{134}$. Finally, HCMV reduces the expression of host miRNAs that suppress ERK and PI3K-AKT-mTORC signalling ${ }^{129}$. Indeed, much remains to be learned about miRNA targets and their contribution to infection.

\section{A potential Achilles heel to exploit for therapy?}

The effectiveness with which viruses co-opt components of the host translation machinery represents an extraordinary example of parasitism and illustrates the importance of this process to viral replication. Nature validates this view, as initiation factors determine plant susceptibility to RNA viruses. Most recessive resistance genes from crop species encode eIF4E and eIF4G family members ${ }^{135}$, and host antiviral factors such as pokeweed antiviral protein bind eIF4G and depurinate viral $\mathrm{RNA}^{136}$. Virus-host interactions that regulate protein synthesis in infected cells could potentially lead to novel broad-spectrum antiviral targets that are ripe for development. Even antagonizing a general factor such as eIF4F may be tolerated for limited periods to combat acute, life-threatening infections, as high eIF4F activity seems to be reserved for translating complex, growth-related mRNAs. 4EGi-1, a synthetic inhibitor that affects eIF4F and ribosome binding, has potent, non-cytotoxic antiviral properties against $\mathrm{HSV}-1$ and $\mathrm{VacV}^{42}$; screens using small interfering RNAs suggest initiation factors and ribosomal proteins as potential antiviral targets ${ }^{137,138}$; and compounds that inhibit eIF2 $\alpha$ dephosphorylation reduce HSV-1 replication $^{139}$. Furthermore, a small-molecule inhibitor of the MNK proteins reduces replication of $\mathrm{VacV}^{38}, \mathrm{ASFV}^{41}$ and several herpesviruses in culture ${ }^{35,37}$. The MNK proteins are interesting targets, as they are not essential, core initiation factors but instead have a regulatory role. Other targets, such as inhibitors of the mTOR active site (which disrupt eIF4F and impair herpesviral replication ${ }^{43}$ ), will probably have immunosuppressive side effects in $v i v o^{140}$. However, inhibiting a virally encoded mTOR activator, such as the HSV-1 kinase US3 (REF. 44), could prevent mTORC1 activation selectively in infected cells and circumvent this problem. IRESs, which are relied on by many RNA viruses, also represent potential targets ${ }^{141-143}$. Finally, virus-host interactions that regulate translation have contributed to the development of oncolytic viruses ${ }^{144}$. 


\section{Summary}

Viruses subvert nearly every step in the host translation process. From mRNA availability for cytoplasmic ribosomes, to cell-signalling pathways that regulate translation factor abundance, localization and activity, to ribosome recruitment, all are commandeered to stimulate and sustain viral mRNA translation. The diversity of strategies used by different viruses reflects the varied viral life cycles, the specialized host cells that viruses infect and the methods of translation control in their cellular hosts (which are probably the main evolutionary drivers behind the diverse strategies used for subversion). Similarities between the translation control strategies that are operative in infected cells and in stress-induced, uninfected cells have emerged. Adenovirus-infected and uninfected, heat-stressed cells use ribosome shunting. Related viral and cellular regulatory phosphatase subunits are required to prevent accumulation of phosphorylated eIF2 $\alpha$ in HSVinfected cells and in uninfected cells recovering from endoplasmic reticulum stress. eIF4G can be cleaved by virally encoded proteases and also by cellular caspases during apoptosis. Key integrators such as TSC and mTORC proteins, which enable rapid control of cap-dependent translation in response to physiological cues in uninfected cells, have important roles stimulating or repressing translation in virus-infected cells. IRESs were originally discovered as viral genetic elements, but they enable translation of cellular mRNAs when eIF4F-mediated, cap-dependent translation is impaired by stress. By conferring eIF2 independence, newly identified factors such as ligatin could expand the range of conditions that support viral mRNA translation. Roles for specific (that is, RPS25) or modified ribosomal proteins may emerge for different viral and cellular IRESs. Finally, IRESs with minimal initiation factor requirements (such as those of $\mathrm{HCV}$ and CrPV) highlight how viral models provide powerful cellbiological and genetic tools that continue to expose surprising translation regulatory mechanisms.
1. Jackson, R. J., Hellen, C. U. \& Pestova, T. V. The mechanism of eukaryotic translation initiation and principles of its regulation. Nature Rev. Mol. Cell Biol. 11, 113-127 (2010)

2. Herbert, T. P. \& Proud, C. G. in Translational Control in Biology and Medicine (eds Mathews, M. B., Sonenberg, N. \& Hershey, J. W. B.) 601-624 (Cold Spring Harbor Laboratory Press, New York, 2007)

3. Dinman, J. D. \& Berry, M. J. in Translational Control in Biology and Medicine (eds Mathews, M. B. Sonenberg, N. \& Hershey, J. W. B.) 625-654 (Cold Spring Harbor Laboratory Press, New York, 2007). 4. Parrish, S. \& Moss, B. Characterization of a second vaccinia virus mRNA-decapping enzyme conserved in poxviruses. J. Virol. 81, 12973-12978 (2007).

5. Parrish, S., Resch, W. \& Moss, B. Vaccinia virus D10 protein has mRNA decapping activity, providing a mechanism for control of host and viral gene expression. Proc. Natl Acad. Sci. USA 104 2139-2144 (2007)

6 Plotch, S. J., Bouloy, M., Ulmanen, I. \& Krug, R. M A unique $\mathrm{cap}\left(\mathrm{m}^{7} \mathrm{Gpp} \mathrm{Xm}\right)$-dependent influenza virion endonuclease cleaves capped RNAs to generate the primers that initiate viral RNA transcription. Cell 23 , 847-858 (1981)

7. Mir, M. A., Duran, W. A., Hjelle, B. L., Ye, C. \& Panganiban, A. T. Storage of cellular $5^{\prime}$ mRNA caps in P bodies for viral cap-snatching. Proc. Natl Acad. Sci. USA 105, 19294-19299 (2008).

8. Dias, A. et al. The cap-snatching endonuclease of influenza virus polymerase resides in the PA subunit. Nature 458, 914-918 (2009)

9. Burgui, I., Yanguez, E., Sonenberg, N. \& Nieto, A Influenza virus mRNA translation revisited: is the elF4E cap-binding factor required for viral mRNA translation? J. Virol 81, 12427-12438 (2007).

10. Goodfellow, I. et al. Calicivirus translation initiation requires an interaction between VPg and elF4E. EMBO Rep. 6, 968-972 (2005).

11. Daughenbaugh, K. F., Fraser, C. S., Hershey, J. W. \& Hardy, M. E. The genome-linked protein VPg of the Norwalk virus binds elF3, suggesting its role in translation initiation complex recruitment. $E M B O \mathrm{~J}$. 22, 2852-2859 (2003).

12. Khan, M. A., Miyoshi, H., Gallie, D. R. \& Goss, D. J. Potyvirus genome-linked protein, VPg, directly affects wheat germ in vitro translation: interactions with translation initiation factors elF4F and elFiso4F. J. Biol. Chem. 283, 1340-1349 (2008).

13. Gallie, D. R. Cap-independent translation conferred by the $5^{\prime}$ leader of tobacco etch virus is eukaryotic initiation factor $4 \mathrm{G}$ dependent. J. Virol. 75 12141-12152 (2001).

14. Miller, W. A., Wang, Z. \& Treder, K. The amazing diversity of cap-independent translation elements in the 3'-untranslated regions of plant viral RNAs. Biochem. Soc. Trans. 35, 1629-1633 (2007).
15. Zuo, X. et al. Solution structure of the capindependent translational enhancer and ribosomebinding element in the $3^{\prime}$ UTR of turnip crinkle virus. Proc. Natl Acad. Sci. USA 107, 1385-1390 (2010).

16. Mir, M. A. \& Panganiban, A. T. A protein that replaces the entire cellular elF4F complex. EMBO J. 27, 3129-3139 (2008)

17. Lloyd, R. E. Translational control by viral proteinases Virus Res. 119, 76-88 (2006).

18. Hellen, C. U. IRES-induced conformational changes in the ribosome and the mechanism of translation initiation by internal ribosomal entry. Biochim. Biophys. Acta 1789, 558-570 (2009).

19. Grainger, L. et al. Stress-inducible alternative translation initiation of human cytomegalovirus latency protein pUL138. J. Virol. 84, 9472-9486 (2010).

20. Griffiths, A. \& Coen, D. M. An unusual internal ribosome entry site in the herpes simplex virus thymidine kinase gene. Proc. Natl Acad. Sci. USA 102 9667-9672 (2005)

21. Yu, Y. \& Alwine, J. C. 19S late mRNAs of simian virus 40 have an internal ribosome entry site upstream of the virion structural protein 3 coding sequence. J. Virol. 80, 6553-6558 (2006).

22. Gingras, A. C., Svitkin, Y., Belsham, G. J., Pause, A. \& Sonenberg, N. Activation of the translational suppressor 4E-BP1 following infection with encephalomyocarditis virus and poliovirus. Proc. Nat Acad. Sci. USA 93, 5578-5583 (1996).

23. Connor, J. H. \& Lyles, D. S. Vesicular stomatitis virus infection alters the elF4F translation initiation complex and causes dephosphorylation of the elF4E binding protein 4E-BP1.J. Virol. 76, 10177-10187 (2002)

24. Dunn, E. F. \& Connor, J. H. Dominant inhibition of Akt/ protein kinase $\mathrm{B}$ signaling by the matrix protein of a negative-strand RNA virus. J. Virol. 85, 422-431 (2011).

25. Buchkovich, N. J., Yu, Y., Zampieri, C. A. \& Alwine, $J$. C. The TORrid affairs of viruses: effects of mammalian DNA viruses on the PI3K-Akt-mTOR signalling pathway. Nature Rev. Microbiol. 6, 266-275 (2008).

A comprehensive review illustrating how DNA viruses control the cellular PI3K-AKT-mTORC signalling axis.

26. Colina, R. et al. Translational control of the innate immune response through IRF-7. Nature $\mathbf{4 5 2}$ 323-328 (2008).

27. Xi, Q., Cuesta, R. \& Schneider, R. J. Tethering of elF4C to adenoviral mRNAs by viral $100 \mathrm{k}$ protein drives ribosome shunting. Genes Dev. 18, 1997-2009 (2004)

28. Feigenblum, D. \& Schneider, R. J. Modification of eukaryotic initiation factor $4 \mathrm{~F}$ during infection by influenza virus. J. Virol. 67, 3027-3035 (1993)

29. Yueh, A. \& Schneider, R. J. Selective translation initiation by ribosome jumping in adenovirus-infected and heat-shocked cells. Genes Dev. 10, 1557-1567 (1996)

30. Yueh, A. \& Schneider, R. J. Translation by ribosome shunting on adenovirus and hsp70 mRNAs facilitated by complementarity to $18 \mathrm{~S}$ rRNA. Genes Dev. 14 414-421 (2000)

Together with references 27 and 29 , an article that provides a comprehensive analysis of ribosomes shunting in uninfected and adenovirus-infected cells.

31. Ryabova, L. A. \& Hohn, T. Ribosome shunting in the cauliflower mosaic virus 35S RNA leader is a special case of reinitiation of translation functioning in plant and animal systems. Genes Dev. 14, 817-829 (2000).

A demonstration that shunting in the CaMV 35S RNA leader involves translation of a small uORF followed by re-initiation downstream of the ribosomal-shunt landing site.

32. Smith, R. W. \& Gray, N. K. Poly(A)-binding protein (PABP): a common viral target. Biochem. J. 426 $1-12(2010)$

33. Montero, H., Arias, C. F. \& Lopez, S. Rotavirus Nonstructural Protein NSP3 is not required for vira protein synthesis. J. Virol. 80, 9031-9038 (2006).

34. Okumura, F., Zou, W. \& Zhang, D. E. ISG15 modification of the elF4E cognate 4EHP enhances cap structure-binding activity of 4EHP. Genes Dev. 21 255-260 (2007)

35. Walsh, D. \& Mohr, I. Phosphorylation of elF4E by Mnk-1 enhances HSV-1 translation and replication in quiescent cells. Genes Dev. 18, 660-672 (2004). A report providing the first evidence that DNA viruses can stimulate eIF4F activity to enhance vira replication.

36. Kudchodkar, S. B., Yu, Y Maguire, T. G, \& Alwine, J. C. Human cytomegalovirus infection induces rapamycininsensitive phosphorylation of downstream effectors of mTOR kinase. J. Virol. 78, 11030-11039 (2004).

37. Walsh, D., Perez, C., Notary, J. \& Mohr, I. Regulation of the translation initiation factor elF4F by multiple mechanisms in human cytomegalovirus-infected cells. J. Virol. 79, 8057-8064 (2005)

38. Walsh, D. et al. Eukaryotic translation initiation factor 4F architectural alterations accompany translation initiation factor redistribution in poxvirus-infected cells. Mol. Cell. Biol. 28, 2648-2658 (2008).

39. Zaborowska, I. \& Walsh, D. PI3K signaling regulates rapamycin-insensitive translation initiation complex formation in vaccinia virus-infected cells. J. Virol. 83 , 3988-3992 (2009).

40. Arias, C. Walsh D Harbell, J., Wilson, A. C \& Mohr, I. Activation of host translational control pathways by a viral developmental switch. PLOS Pathog. 5, e1000334 (2009).

41 Castelló, A et al Regulation of host translational machinery by african Swine Fever virus. PLoS Pathog. 5, e 1000562 (2009). 
42. McMahon, R, Zaborowska, I. \& Walsh, D. Noncytotoxic inhibition of viral infection through elF4F-independent suppression of translation by 4EGi-1. J. Virol. 85, 853-864 (2011).

43. Moorman, N. J. \& Shenk, T. Rapamycin-resistant mTORC 1 activity is required for herpesvirus replication. J. Virol. 84, 5260-5269 (2010)

44. Chuluunbaatar, U. et al. Constitutive mTORC1 activation by a herpesvirus Akt surrogate stimulates mRNA translation and viral replication. Genes Dev. 24, 2627-2639 (2010)

45. Perez, C., McKinney, C., Chulunbaatar, U. \& Mohr, I. Translational control of the abundance of cytoplasmic poly(A) binding protein in human cytomegalovirusinfected cells. J. Virol. 85, 156-164 (2011).

46. Moorman, N. J. et al. Human cytomegalovirus protein UL38 inhibits host cell stress responses by antagonizing the tuberous sclerosis protein complex. Cell Host Microbe 3, 253-262 (2008).

47. Clippinger, A. J., Maguire, T. G. \& Alwine, J. C. The changing role of mammalian target of rapamycin (mTOR) kinase in the maintenance of protein synthesis during human cytomegalovirus infection. J. Virol. 85, 3930-3939 (2011)

48. O'Shea, C et al Adenoviral proteins mimic nutrient/ growth signals to activate the mTOR pathway for viral replication. EMBO J. 24, 1211-1221 (2005).

49. Spangle, J. M. \& Munger, K. The human papillomavirus type $16 \mathrm{E} 6$ oncoprotein activates mTORC1 signaling and increases protein synthesis. J. Virol. 84, 9398-9407 (2010).

50. Werden, S. J., Barrett, J. W., Wang, G., Stanford, M. M. \& McFadden, G. M-T5, the ankyrin repeat, host range protein of myxoma virus, activates Akt and can be functionally replaced by cellular PIKE-A. J. Virol. 81, 2340-2348 (2007)

51. Braunstein, S., Badura, M. L., Xi, Q., Formenti, S. C. \& Schneider, R. J. Regulation of protein synthesis by ionizing radiation. Mol. Cell. Biol. 29, 5645-5656 (2009).

52. Elia, A., Constantinou, C. \& Clemens, M. J. Effects of protein phosphorylation on ubiquitination and stability of the translational inhibitor protein $4 \mathrm{E}-\mathrm{BP} 1$ Oncogene 27, 811-822 (2008).

53. Walsh, D. \& Mohr I. Assembly of an active translation initiation factor complex by a viral protein. Genes Dev. 20, 461-472 (2006).

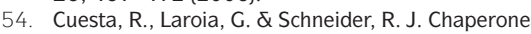 hsp27 inhibits translation during heat shock by binding elF4G and facilitating dissociation of capinitiation complexes. Genes Dev. 14, 1460-1470 (2000).

55. Dobrikova, E., Shveygert, M., Walters, R. \& Gromeier, M Herpes simplex virus proteins ICP27 and UL47 associate with polyadenylate-binding protein and control its subcellular distribution. J. Virol. 84 270-279 (2010)

56. Sandri-Goldin, R. M. in Alphaherpesviruses: Molecular Virology (ed. Weller, S.) 39-50 (Caister Academic, Norfolk, 2011).

57. Raoult, D. et al. The 1.2-megabase genome sequence of Mimivirus. Science 306, 1344-1350 (2004).

58. Katsafanas, G. C. \& Moss, B. Colocalization of transcription and translation within cytoplasmic poxvirus factories coordinates viral expression and subjugates host functions. Cell Host Microbe 2 221-228 (2007)

Along with reference 38 , a demonstration that elF proteins are recruited into and concentrated within cytoplasmic replication compartments.

59. Thivierge, K. et al. Eukaryotic elongation factor $1 \mathrm{~A}$ interacts with Turnip mosaic virus RNA-dependent RNA polymerase and VPg-Pro in virus-induced vesicles. Virology 377, 216-225 (2008).

60. Sanz, M. A., Castello, A., Ventoso, I., Berlanga, J. J. \& Carrasco, L. Dual mechanism for the translation of subgenomic mRNA from Sindbis virus in infected and uninfected cells. PLOS ONE 4, e4772 (2009).

61. Sukarieh, R., Sonenberg, N. \& Pelletier, J. Nuclear assortment of elF4E coincides with shut-off of host protein synthesis upon poliovirus infection. J. Gen. Virol. 91, 1224-1228 (2010)

62. Harb, M. et al. Nuclear localization of cytoplasmic poly(A)-binding protein upon rotavirus infection involves the interaction of NSP3 with elF4G and RoXaN. J. Virol. 82, 11283-11293 (2008).

63. Salaun, C. et al. Poly(A)-binding protein 1 (PABP1) partially relocalises to the nucleus during HSV-1 infection in an ICP27-independent manner and does not inhibit virus replication. J. Virol. 84, 8539-8548 (2010).
64. Clyde, K. \& Glaunsinger, B. A. Getting the message direct manipulation of host mRNA accumulation during gammaherpesvirus lytic infection. Adv. Virus Res. 78, 1-42 (2010)

65. Blakqori, G., van Knippenberg, I. \& Elliott, R. M. Bunyamwera orthobunyavirus S-segment untranslated regions mediate poly(A) tail-independent translation. J. Virol. 83, 3637-3646 (2009).

66. Banerjee, S., Narayanan, K., Mizutani, T. \& Makino, S. Murine coronavirus replication-induced p38 mitogenactivated protein kinase activation promotes interleukin- 6 production and virus replication in cultured cells. J. Virol. 76, 5937-5948 (2002).

67. Wilson, J. E., Pestova, T. V., Hellen, C. U. \& Sarnow, P. Initiation of protein synthesis from the A site of the ribosome. Cell 102, 511-520 (2000).

An elegant demonstration that the CrPV IRES directly recruits ribosomes and initiates translation without eIF proteins.

68. Jan, E. \& Sarnow, P. Factorless ribosome assembly on the internal ribosome entry site of cricket paralysis virus. J. Mol. Biol. 324, 889-902 (2002).

69. Fraser, C. S. \& Doudna, J. A. Structural and mechanistic insights into hepatitis C viral translation initiation. Nature Rev. Microbiol. 5, 29-38 (2007).

70. Jackson, R. J., Kaminski, A. \& Poyry, T. A. in Translational Control in Biology and Medicine (eds Mathews, M. B., Sonenberg, N. \& Hershey, J. W. B.) 197-224 (Cold Spring Harbor Laboratory Press, New York, 2007).

71. Pestova, T. V., Shatsky, I. N., Fletcher, S. P., Jackson, R. J. \& Hellen, C. U. A prokaryotic-like mode of cytoplasmic eukaryotic ribosome binding to the initiation codon during internal translation initiation of hepatitis $\mathrm{C}$ and classical swine fever virus RNAs. Genes Dev. 12, 67-83 (1998).

The finding that the requirements for $48 \mathrm{~S}$ pre-initiation complex formation on HCV and CSFV IRESs differ from those of the EMCV IRES, as shown by reconstituting internal ribosome entry in vitro using purified translation components.

72. Locker, N., Chamond, N. \& Sargueil, B. A conserved structure within the HIV gag open reading frame that controls translation initiation directly recruits the $40 \mathrm{~S}$ subunit and elF3. Nucleic Acids Res. 39, 2367-2377 (2010)

73. Skabkin, M. A. et al. Activities of Ligatin and MCT-1/ DENR in eukaryotic translation initiation and ribosomal recycling. Genes Dev. 24, 1787-1801 (2010)

A study identifying cellular factors that substitute for elF2 to mediate initiation on viral IRES elements.

74. Spahn, C. M. et al. Cryo-EM visualization of a viral internal ribosome entry site bound to human ribosomes: the IRES functions as an RNA-based translation factor. Cell 118, 465-475 (2004).

75. Landry, D. M., Hertz, M. I. \& Thompson, S. R. RPS25 is essential for translation initiation by the Dicistroviridae and hepatitis C viral IRESs. Genes Dev. 23, 2753-2764 (2009)

Work establishing that a cellular ribosomal protein is specifically required for IRES-mediated translation.

76. Schepetilnikov, M et al. Viral factor TAV recruits TOR/ S6K1 signalling to activate reinitiation after long ORF translation. EMBO J. 30, 1343-1356 (2011) The demonstration that plant-virus proteins recruit TOR proteins (the plant homologues of $\mathrm{mTOR}$ proteins) and interact with translation factors to control re-initiation.

77. Sato, H. et al. Measles virus N protein inhibits host translation by binding to elF3-p40. J. Virol. 81 , 11569-11576 (2007).

78. Komarova, A. V. et al. Rabies virus matrix protein interplay with elF3, new insights into rabies virus pathogenesis. Nucleic Acids Res. 35, 1522-1532 (2007).

79. Rodriguez Pulido, M., Serrano, P., Saiz, M. \& Martinez-Salas, E. Foot-and-mouth disease virus infection induces proteolytic cleavage of PTB, eIF3a, b, and PABP RNA-binding proteins. Virology 364 , 466-474 (2007).

80. Terenzi, F., Hui, D. J., Merrick, W. C. \& Sen, G. C. Distinct induction patterns and functions of two closely related interferon-inducible human genes, ISG54 and ISG56. J. Biol. Chem. 281, 34064-34071 (2006).

81. Mohr, I. J., Pe'ery, T. \& Mathews, M. B. in Translational Control in Biology and Medicine (eds Mathews, M. B., Sonenberg, N. \& Hershey, J. W. B.) 545-595 (Cold Spring Harbor Laboratory Press, New York, 2007).
82. Talloczy, Z. et al. Regulation of starvation- and virusinduced autophagy by the elF2 $\alpha$ kinase signaling pathway. Proc. Natl Acad. Sci. USA 99, 190-195 (2002).

83. Zhang, F., Moon, A., Childs, K., Goodbourn, S. \& Dixon, L. K. The African swine fever virus DP71L protein recruits the protein phosphatase 1 catalytic subunit to dephosphorylate elF2 $\alpha$ and inhibits CHOP induction but is dispensable for these activities during virus infection. J. Virol. 84, 10681-10689 (2010).

84. He, B., Gross, M. \& Roizman, B. The gamma(1)34.5 protein of herpes simplex virus 1 complexes with protein phosphatase 1 a to dephosphorylate the a subunit of the eukaryotic translation initiation factor 2 and preclude the shutoff of protein synthesis by double-stranded RNA-activated protein kinase. Proc. Natl Acad. Sci. USA 94, 843-848 (1997).

85. Mulvey, M., Poppers, J., Sternberg, D. \& Mohr, I. Regulation of elF2 $\alpha$ phosphorylation by different functions that act during discrete phases in the herpes simplex virus type 1 life cycle. J. Virol. 77, 10917-10928 (2003).

86. Mulvey, M., Arias, C. \& Mohr, I. Maintenance of endoplasmic reticulum (ER) homeostasis in herpes simplex virus type 1 -infected cells through the association of a viral glycoprotein with PERK, a cellular ER stress sensor. J. Virol. 81, 3377-3390 (2007).

87. Sood, R., Porter, A. C., Ma, K., Quilliam, L. A. \& Wek, R. C. Pancreatic eukaryotic initiation factor-2 $\alpha$ kinase (PEK) homologues in humans, Drosophila melanogaster and Caenorhabditis elegans that mediate translational control in response to endoplasmic reticulum stress. Biochem. J. 346 281-293 (2000)

88. Berlanga, J. J. et al. Antiviral effect of the mammalian translation initiation factor $2 a$ kinase GCN2 against RNA viruses. EMBO J. 25, 1730-1740 (2006).

89. Bilgin, D. D., Liu, Y., Schiff, M. \& Dinesh-Kumar, S. P. P58 IPK a plant ortholog of double-stranded RNAdependent protein kinase PKR inhibitor, functions in viral pathogenesis. Dev. Cell 4, 651-661 (2003).

90. Goodman, A. G. et al. P58 IPK: a novel "CIHD" member of the host innate defense response against pathogenic virus infection. PLoS Pathog. 5, e1000438 (2009).

91. Garaigorta, U. \& Chisari, F. V. Hepatitis C virus blocks interferon effector function by inducing protein kinase R phosphorylation. Cell Host Microbe 6, 513-522 (2009).

92. Ventoso, I. et al. Translational resistance of late alphavirus mRNA to elF2 $\alpha$ phosphorylation: a strategy to overcome the antiviral effect of protein kinase PKR. Genes Dev. 20, 87-100 (2006).

The identification of a viral genetic element that supports translation initiation in the presence of phosphorylated elF2 $\alpha$.

93. Jordan, R., Wang, L., Graczyk, T. M., Block, T. M. \& Romano, P. R. Replication of a cytopathic strain of bovine viral diarrhea virus activates PERK and induces endoplasmic reticulum stress-mediated apoptosis of MDBK cells. J. Virol. 76, 9588-9599 (2002).

94. Smith, J. A. et al. Reovirus induces and benefits from an integrated cellular stress response. J. Virol. 80, 2019-2033 (2006)

95. Montero, H., Rojas, M., Arias, C. F. \& Lopez, S. Rotavirus infection induces the phosphorylation of elF2 $\alpha$ but prevents the formation of stress granules. J. Virol. 82, 1496-1504 (2008)

96. Beckham, C. J. \& Parker, R. P bodies, stress granules, and viral life cycles. Cell Host Microbe 3, 206-212 (2008).

97. O'Neill, R. E. \& Racaniello, V. R. Inhibition of translation in cells infected with a poliovirus 2 Apro mutant correlates with phosphorylation of the alpha subunit of eucaryotic initiation factor 2. J. Virol. 63, 5069-5075 (1989).

98. Garrey, J. L., Lee, Y. Y., Au, H. H., Bushell, M. \& Jan, E. Host and viral translational mechanisms during cricket paralysis virus infection. J. Virol. 84, 1124-1138 (2010).

99. Pestova, T. V., de Breyne, S., Pisarev, A. V., Abaeva, I. S. \& Hellen, C. U. elF2-dependent and elF2-independent modes of initiation on the CSFV IRES: a common role of domain II. EMBO J. 27 1060-1072 (2008)

100. Lancaster, A. M., Jan, E. \& Sarnow, P. Initiation factorindependent translation mediated by the hepatitis $\mathrm{C}$ virus internal ribosome entry site. RNA 12, 894-902 (2006). 
101. Dmitriev, S. E. et al. GTP-independent tRNA delivery to the ribosomal P-site by a novel eukaryotic translation factor. J. Biol. Chem. 285, 26779-26787 (2010).

102. de Breyne, S., Bonderoff, J. M., Chumakov, K. M., Lloyd, R. E. \& Hellen, C. U. Cleavage of eukaryotic initiation factor elF5B by enterovirus $3 \mathrm{C}$ proteases. Virology 378, 118-122 (2008).

103. Zhou, B. et al. The nucleocapsid protein of severe acute respiratory syndrome coronavirus inhibits cell cytokinesis and proliferation by interacting with translation elongation factor 1 a. J. Virol. 82, 6962-6971 (2008).

104. Ji, W. T., Wang, L., Lin, R. C., Huang, W. R. \& Liu, H. J. Avian reovirus influences phosphorylation of several factors involved in host protein translation including eukaryotic translation elongation factor 2 (eEF2) in Vero cells. Biochem. Biophys. Res. Commun. $\mathbf{3 8 4}$ 301-305 (2009).

105. Cimarelli, A. \& Luban, J. Translation elongation factor 1 -alpha interacts specifically with the human immunodeficiency virus type $1 \mathrm{Gag}$ polyprotein. J. Virol. 73, 5388-5401 (1999).

106. Kawaguchi, Y., Matsumura, T., Roizman, B. \& Hirai, K. Cellular elongation factor $1 \delta$ is modified in cells infected with representative alpha-, beta-, or gammaherpesviruses. J. Virol. 73, 4456-4460 (1999).

107. Sonenberg, N. \& Hinnebusch, A. G. Regulation of translation initiation in eukaryotes: mechanisms and biological targets. Cell 136, 731-745 (2009).

108. Napthine, S. et al. Expression of the VP2 protein of murine norovirus by a translation terminationreinitiation strategy. PLOS ONE 4, e8390 (2009).

109. Luttermann, C. \& Meyers, G. The importance of interand intramolecular base pairing for translation reinitiation on a eukaryotic bicistronic mRNA. Genes Dev. 23, 331-344 (2009)

110. Powell, M. L. et al. Further characterisation of the translational termination-reinitiation signal of the influenza B virus segment 7 RNA. PLOS ONE 6 e16822 (2011)

Together with reference 109, an illustration of the role of an RNA sequence element in binding terminating ribosomes to facilitate re-initiation on downstream ORFs.

111. Orlova, M., Yueh, A., Leung, J. \& Goff, S. P. Reverse transcriptase of Moloney murine leukemia virus binds to eukaryotic release factor 1 to modulate suppression of translational termination. Cell 115, 319-331 (2003).

The demonstration that a retroviral protein interacts with eRF1 to regulate re-initiation.

112. Hogg, J. R. \& Goff, S. P. Upf1 senses 3'UTR length to potentiate mRNA decay. Cell 143, 379-389 (2010).

113. Janzen, D. M., Frolova, L. \& Geballe, A. P. Inhibition of translation termination mediated by an interaction of eukaryotic release factor 1 with a nascent peptidyltRNA. Mol. Cell. Biol. 22, 8562-8570 (2002). An article showing that a uORF-encoded peptide binds eRF 1 , inhibiting termination of uORF mRNA translation and preventing translation of a downstream ORF.

114. Aoyagi, M., Gaspar, M. \& Shenk, T. E. Human cytomegalovirus UL 69 protein facilitates translation by associating with the mRNA cap-binding complex and excluding 4EBP1. Proc. Natl Acad. Sci. USA 107 2640-2645 (2010).

115. Boyne, J. R., Jackson, B. R., Taylor, A., Macnab, S. A. \& Whitehouse, A. Kaposi's sarcoma-associated herpesvirus ORF57 protein interacts with PYM to enhance translation of viral intronless mRNAs. EMBO J. 29, 1851-1864 (2010).

116. Satterly, N. et al. Influenza virus targets the mRNA export machinery and the nuclear pore complex. Proc. Natl Acad. Sci. USA 104, 1853-1858 (2007).

117. Yatherajam, G., Huang, W. \& Flint, S. J. Export of adenoviral late mRNA from the nucleus requires the Nxf1/Tap export receptor. J. Virol. 85, 1429-1438 (2011).

118. Karlas, A. et al. Genome-wide RNAi screen identifies human host factors crucial for influenza virus replication. Nature 463, 818-822 (2010).
119. Faria, P. A. et al. VSV disrupts the Rae $1 / \mathrm{mrnp} 41$ mRNA nuclear export pathway. Mol. Cell 17, 93-102 (2005)

120. Feng, P., Everly, D. N. Jr \& Read, G. S. mRNA decay during herpes simplex virus (HSV) infections: protein protein interactions involving the HSV virion host shutoff protein and translation factors elF $4 \mathrm{H}$ and elF4A. J. Virol. 79, 9651-9664 (2005).

121. White, J. P., Cardenas, A. M., Marissen, W. E. \& Lloyd, R. E. Inhibition of cytoplasmic mRNA stress granule formation by a viral proteinase. Cell Host Microbe 2 295-305 (2007).

122. Dougherty, J. D., White, J. P. \& Lloyd, R. E. Poliovirusmediated disruption of cytoplasmic processing bodies. J. Virol. 85, 64-75 (2011).

123. Piotrowska, J. et al. Stable formation of compositionally unique stress granules in virusinfected cells. J. Virol. 84, 3654-3665 (2010).

124. Khong, A. $\&$ Jan, E. Modulation of stress granules and P bodies during dicistrovirus infection. J. Virol. 85, 1439-1451 (2011)

125. Qin, Q., Hastings, C. \& Miller, C. L. Mammalian orthoreovirus particles induce and are recruited into stress granules at early times postinfection. J. Virol. 83, 11090-11101 (2009).

126. Lindquist, M. E., Lifland, A. W., Utley, T. J., Santangelo, P. J. \& Crowe, J. E. Jr. Respiratory syncytial virus induces host RNA stress granules to facilitate viral replication. J. Virol. 84, 12274-12284 (2010).

127. Nathans, R. et al. Cellular microRNA and P bodies modulate host-HIV-1 interactions. Mol. Cell 34 696-709 (2009)

128. Simpson-Holley, M. et al. Formation of antiviral cytoplasmic granules during orthopoxvirus infection J. Virol. 85, 1581-1593 (2011)

129. Skalsky, R. L. \& Cullen, B. R. Viruses, microRNAs, and host interactions. Annu. Rev. Microbiol. 64, 123-141 (2010).

A comprehensive review of virally encoded miRNAs.

130. Ho, B. C. et al. Enterovirus-induced miR-141 contributes to shutoff of host protein translation by targeting the translation initiation factor elF4E. Cell Host Microbe 9, 58-69 (2010)

The discovery that a host miRNA can be exploited by a virus to target elF4E and suppress host protein synthesis.

131. Jopling, C. L., Yi, M., Lancaster, A. M., Lemon, S. M. \& Sarnow, P. Modulation of hepatitis C virus RNA abundance by a liver-specific microRNA. Science 309, 1577-1581 (2005)

132. Jangra, R. K., Yi, M. \& Lemon, S. M. Regulation of hepatitis $C$ virus translation and infectious virus production by the microRNA miR-122. J. Virol. 84 6615-6625 (2010)

133. Henke, J. I. et al. microRNA-122 stimulates translation of hepatitis C virus RNA. EMBO J. 27 3300-3310 (2008)

134. Jopling, C. L., Schutz, S. \& Sarnow, P. Position dependent function for a tandem microRNA miR-122-binding site located in the hepatitis $C$ virus RNA genome. Cell Host Microbe 4, 77-85 (2008).

135. Truniger, V. \& Aranda, M. A. Recessive resistance to plant viruses. Adv. Virus Res. 75, 119-159 (2009).

136. Wang, M. \& Hudak, K. A. A novel interaction of pokeweed antiviral protein with translation initiation factors 4G and iso4G: a potential indirect mechanism to access viral RNAs. Nucleic Acids Res. 34, 1174-1181 (2006).

137. Cherry, S. et al. Genome-wide RNAi screen reveals a specific sensitivity of IRES-containing RNA viruses to host translation inhibition. Genes Dev 19, 445-452 (2005)

138. Welnowska, E., Castelló, A., Moral, P. \& Carrasco, L. Translation of mRNAs from vesicular stomatitis virus and vaccinia virus is differentially blocked in cells with depletion of elF4GI and/or elF4GII. J. Mol. Biol. 394 506-521 (2009).

139. Boyce, M. et al. A selective inhibitor of elF $2 \alpha$ dephosphorylation protects cells from ER stress. Science 307, 935-939 (2005).

140. Sehgal, S. N. Sirolimus: its discovery, biological properties, and mechanism of action. Transplant Proc. 35, S7-S14 (2003)
141. Bordeleau, M. E. et al. Functional characterization of IRESes by an inhibitor of the RNA helicase elF4A. Nature Chem. Biol. 2, 213-220 (2006).

142. Paulsen, R. B. et al. Inhibitor-induced structural change in the HCV IRES domain Ila RNA. Proc. Nat Acad. Sci. USA 107, 7263-7268 (2010).

143. Novac, O., Guenier, A. S. \& Pelletier, J. Inhibitors of protein synthesis identified by a high throughput multiplexed translation screen. Nucleic Acids Res. 32, 902-915 (2004)

144. Mohr I. To replicate or not to replicate: achieving selective oncolytic virus replication in cancer cells through translational control. Oncogene 24, 7697-7709 (2005).

145. McCarthy, J. E. \& Gualerzi, C. Translational control of prokaryotic gene expression. Trends Genet. 6, 78-85 (1990).

146. Uzan, M. RNA processing and decay in bacteriophage T4. Prog. Mol. Biol. Transl. Sci. 85, 43-89 (2009).

147. Casjens, S., Adams, M. B., Hall, C. \& King, J. Assembly-controlled autogenous modulation of bacteriophage P22 scaffolding protein gene expression. J. Virol. 53, 174-179 (1985).

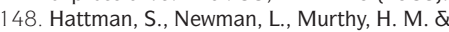 Nagaraja, V. Com, the phage Mu mom translational activator, is a zinc-binding protein that binds specifically to its cognate mRNA. Proc. Natl Acad. Sci. USA 88, 10027-10031 (1991).

149. Saito, H. \& Richardson, C. C. Processing of mRNA by ribonuclease III regulates expression of gene 1.2 of bacteriophage T7. Cell 27, 533-542 (1981)

150. Ivey-Hoyle, M. \& Steege, D. A. Translation of phage f1 gene VII occurs from an inherently defective initiation site made functional by coupling. J. Mol. Biol. 208 233-244 (1989).

151. Inokuchi, Y., Hirashima, A., Sekine, Y., Janosi, L. \& Kaji, A. Role of ribosome recycling factor (RRF) in translational coupling. EMBO J. 19, 3788-3798 (2000).

152. Xu, J., Hendrix, R. W. \& Duda, R. L. Conserved translational frameshift in dsDNA bacteriophage tail assembly genes. Mol. Cell 16, 11-21 (2004)

153. Wills, N. M. et al. Translational bypassing without peptidyl-tRNA anticodon scanning of coding gap mRNA. EMBO J. 27, 2533-2544 (2008).

A paper examining how translating ribosomes can skip over or bypass mRNA segments and resume translation at a downstream site.

154. Oppenheim, A. B., Kornitzer, D., Altuvia, S. \& Court, D. L. Posttranscriptional control of the lysogenic pathway in bacteriophage lambda. Prog. Nucleic Acid Res. Mol. Biol. 46, 37-49 (1993).

155. Wilson, H. R., Yu, D., Peters, H. K. 3rd, Zhou, J. G. \& Court, D. L. The global regulator RNase III modulates translation repression by the transcription elongation factor N. EMBO J. 21, 4154-4161 (2002).

156. Biere, A. L., Citron, M. \& Schuster, H. Transcriptional control via translational repression by $c 4$ antisense RNA of bacteriophages P1 and P7. Genes Dev. 6 2409-2416 (1992)

157. Bidnenko, E., Chopin, A., Ehrlich, S. D. \& Chopin, M. C. Activation of mRNA translation by phage protein and low temperature: the case of Lactococcus lactis abortive infection system AbiD1. BMC Mol. Biol. 10, 4 (2009).

Acknowledgements

The authors apologize to the many colleagues whose work is not cited directly here owing to space restrictions. In addition, they thank U. Chuluunbaatar and L. Shiflett for critical reading of the manuscript Grants from the US National Institutes of Health (I.M.), Science Foundation Ireland (D.W.) and the Irish Health Research Board (D.W.) funded research in the authors' laboratories.

Competing interests statement

The authors declare no competing financial interests.

\section{FURTHER INFORMATION}

lan Mohr's homepage:

http://microbiology-parasitology.med.nyu.edu/node/124

ALL LINKS ARE ACTIVE IN THE ONLINE PDF 